\title{
Treatment of Non-Infectious Corneal Injury: Review of Diagnostic Agents, Therapeutic Medications, and Future Targets
}

\author{
Deanna H. Dang ${ }^{1} \cdot$ Kamran M. Riaz ${ }^{1} \cdot$ Dimitrios Karamichos $^{2,3,4}$
}

Accepted: 2 December 2021 / Published online: 13 January 2022

(c) The Author(s) 2022

\begin{abstract}
Corneal injuries can occur secondary to traumatic, chemical, inflammatory, metabolic, autoimmune, and iatrogenic causes. Ocular infection may frequently occur concurrent to corneal injury; however, antimicrobial agents are excluded from this present review. While practitioners may primarily rely on clinical examination techniques to assess these injuries, several pharmacological agents, such as fluorescein, lissamine green, and rose bengal, can be used to formulate a diagnosis and develop effective treatment strategies. Practitioners may choose from several analgesic medications to help with patient comfort without risking further injury or delaying ocular healing. Atropine, cyclopentolate, scopolamine, and homatropine are among the most frequently used medications for this purpose. Additional topical analgesic agents may be used judiciously to augment patient comfort to facilitate diagnosis. Steroidal anti-inflammatory agents are frequently used as part of the therapeutic regimen. A variety of commonly used agents, including prednisolone acetate, loteprednol, difluprednate, dexamethasone, fluorometholone, and methylprednisolone are discussed. While these medications are effective for controlling ocular inflammation, side effects, such as elevated intraocular pressure and cataract formation, must be monitored by clinicians. Non-steroidal medications, such as ketorolac, bromfenac, nepafenac, and diclofenac, are additionally used for their efficacy in controlling ocular inflammation without incurring side effects seen with steroids. However, these agents have their own respective side effects, warranting close monitoring by clinicians. Additionally, ophthalmologists routinely employ several agents in an off-label manner for supplementary control of inflammation and treatment of corneal injuries. Patients with corneal injuries not infrequently have significant ocular surface disease, either as a concurrent pathology or as an exacerbation of previously existing disease. Several agents used in the management of ocular surface disease have also been found to be useful as part of the therapeutic armamentarium for treatment of corneal injuries. For example, several antibiotics, such as doxycycline and macrolides, have been used for their anti-inflammatory effects on specific cytokines that are upregulated during acute injuries. There has been a recent wave of interest in amniotic membrane therapies (AMTs), including topical, cryopreserved and dehydrated variants. AMT is particularly effective in ocular injuries with violation of corneal surface integrity due to its ability to promote reepithelialization of the corneal epithelium. Blood-based therapies, including autologous serum tears, plasma-enriched growth factor eyedrops and autologous blood drops, have additionally been explored in small case series for effectiveness in challenging and recalcitrant cases. Protection of the ocular surface is also a vital component in the treatment of corneal injuries. Temporary protective methods, such as bandage contact lenses and mechanical closure of the eyelids (tarsorrhaphy) can be particularly helpful in selective cases. Glue therapies, including biologic and non-biologic variants, can also be used in cases of severe injury and risk of corneal perforation. Finally, there are a variety of recently introduced and in-development agents that may be used as adjuvant therapies in challenging patient populations. Neurotrophic corneal disease may occur as a result of severe or chronic injury. In such cases, recombinant human nerve growth factor (cenegermin), topical insulin, and several other novel agents may be an alternate and effective option for clinicians to consider.
\end{abstract}

\section{Introduction}

Corneal wound healing involves several complex pathways that can be targeted by drugs with varying mechanisms of action. Furthermore, corneal sensitivity and pain are due to the high

Extended author information available on the last page of the article density of the nerve endings in the cornea [1]. Corneal injuries can affect these nerves resulting in dry eye disease due to reduced blinking, altered tear production, and impaired release of trophic factors, which are necessary to maintain the structural and functional integrity of the cornea. Agents that numb the surface of the eye are imperative to achieving a proper diagnosis in addition to providing optimal management. 


\section{Key Points}

A variety of cycloplegic, anti-inflammatory agents, and off-label use oral drugs are used in the treatment of noninfectious corneal injuries.

Various mechanical barrier therapies, amniotic membrane therapies (AMTs), and blood-based therapies have gained significant attention recently for their usefulness in facilitating corneal wound healing.

A number of novel agents with good preclinical profiles remain an area of future investigation and interest as effective adjunctive and solo therapies.

Currently, there lacks a compendium-style article on current and recently developed corneal agents. This article is intended to concisely summarize each diagnostic and therapeutic agent to assist clinicians encountering this challenging patient population.

There are a variety of agents used for corneal injuries from diagnostic (analgesic and staining agents) to therapeutic medications. With regard to the latter, there are a plethora of drug classes employed by ophthalmologists to control eye pain, combat inflammation, and treat ocular surface disease. Compiling a guide of available corneal agents is challenging due to the vast number of agents, the off-label use of oral agents, and recently developed novel agents. Although lists of ocular agents have been compiled previously in textbooks and other guides, these resources usually only discuss drop therapies without mention of barrier therapies, amniotic membrane therapies (AMTs), blood-based therapies, or novel agents. This compendium-type article would be helpful for both eye-care professionals as well as other providers in treating corneal injuries. The goal of this paper is to provide readers with comprehensive but concise summaries of each agent separated by class as an effective up-to-date reference. Additionally, a brief summary of novel agents, including those currently in development, is included to provide a foundation for approaching and understanding future developments in this field.

\section{Diagnostic Agents}

\subsection{Diagnostic Analgesic Agents}

\subsubsection{Proparacaine $0.5 \%$}

Proparacaine is a topical ophthalmic anesthetic (TOA) used to numb the eye before surgeries, clinical examination, and other minor ocular surface procedures (Table 1). This agent works by antagonizing the function of voltage-gated sodium channels [2]. Anesthesia of corneal epithelium typically occurs within $15 \mathrm{~s}$, which improves patient comfort during examination of the damaged cornea. We recommend proparacaine eyedrops to be used exclusively for diagnostic purposes as opposed to therapeutic use in the setting of cornea injury. The use of dilute or physician-dispensed proparacaine for the treatment of corneal injury, such as corneal abrasions, is highly controversial. While some authors have advocated for limited, supervised use in specific settings, other authors have reported significant injury and infection from topical anesthetic abuse. It is our opinion that patients should not use TOAs for treatment of ocular surface pain [2-6]. Significant corneal injury should instead be referred to an ophthalmologist with experience in medical and surgical treatment of corneal disease. Prolonged use of TOAs can lead to corneal scarring and superimposed infections such as bacterial and/or fungal keratitis [7]. Other complications with prolonged use of TOAs include corneal epithelial defects, stromal infiltrates, ring-shaped keratitis, and hypopyon, especially in patients with work-related injuries [7].

\subsubsection{Tetracaine $0.5 \%$}

Tetracaine is another TOA used for diagnostic purposes similar to proparacaine. At $0.5 \%$ concentration, tetracaine hydrochloride solution is a clear and colorless solution that can be used for procedures requiring a rapid and short-acting ophthalmic anesthetic. Practitioners may choose between either proparacaine or tetracaine. Although this agent can be stored at room temperature or refrigerated, cold tetracaine causes less burning sensation upon instillation [8,9]. As a result, it is recommended that this drug is refrigerated if used in routine practice. Some practitioners use a combination of proparacaine and tetracaine for minor in-office procedures, such as removal of corneal foreign bodies at the slit-lamp for additional anesthesia.

\subsubsection{Lidocaine}

Lidocaine may be given as a solution (1-4\%) or gel $(2 \%)$ formulation and works as a local anesthetic agent by stabilizing the neuronal membrane by inhibiting the ionic fluxes required for the initiation and conduction of impulses [10]. Anesthesia generally occurs between $20 \mathrm{~s}$ and $1 \mathrm{~min}$ with effects lasting from 5 to $30 \mathrm{~min}$. When compared to tetracaine, $4 \%$ lidocaine resulted in a significantly prolonged topical anesthetic effect, making it a potentially useful agent when longer duration of anesthetic effect is desired for diagnostic or treatment purposes [11]. Some clinicians utilize 
Table 1 Overview of diagnostic analgesic agents regarding purpose, onset of action, duration of action and other notes

\begin{tabular}{|c|c|c|c|c|}
\hline Diagnostic agent & Purpose & Onset & Duration & Other notes \\
\hline Proparacaine $0.5 \%$ & TOA & $30 \mathrm{~s}$ & $15 \min$ & $\begin{array}{l}\text { Recommend to be used exclusively for diagnostic purposes } \\
\text { Use of dilute or physician-dispensed proparacaine is controversial }\end{array}$ \\
\hline Tetracaine $0.5 \%$ & TOA & $30 \mathrm{~s}$ & $10-20 \mathrm{~min}$ & Cold tetracaine causes less burning sensation \\
\hline Lidocaine & TOA & $30 \mathrm{~s}$ to $1 \mathrm{~min}$ & $5-30 \mathrm{~min}$ & $\begin{array}{l}\text { Available in } 1-4 \% \text { solution or } 2 \% \text { gel formulation } \\
\text { More useful agent when longer duration of anesthetic effect is desired }\end{array}$ \\
\hline
\end{tabular}

lidocaine for in-office diagnostic and therapeutic procedures, such as removal of superficial conjunctival foreign body and/ or intraocular injection of therapeutic agents, when stronger anesthetic effect is required.

\subsection{Diagnostic Staining Agents}

\subsubsection{Fluorescein}

This agent is used to stain the cornea to detect abrasions and other eye abnormalities (Fig. 1). In cases of traumatic injury in which there is a clinical concern for corneal perforation and/or wound leak, fluorescein strips can be used for Seidel testing to aid the practitioner in determining the presence of a compromised wound. Fluorescein is also available as a stock solution available in multiple-use bottles (Table 2). In the setting of corneal injury, we recommend the use of strips rather than solution due to advantages such as allowing for Seidel testing, convenience, and decreasing risk of bacterial contamination associated with multiple-use fluorescein bottles, notable with Pseudomonas species [12]. The strips are moistened with sterile water, saline, or a TOA, then applied to the palpebral conjunctiva. Care should be given to avoid contact with the bulbar conjunctiva or the cornea directly, unless specifically used for Seidel testing, in order to avoid additional injury. After application, shining cobalt blue light to the eye can aid the clinician in detecting corneal defects by marking denuded epithelium with a bright green hue. Fluorescein is generally considered safe. However, a case report detailed a patient developing syncope and anaphylactic shock 3 min after receiving topical fluorescein in the eye [12].

\subsubsection{Lissamine Green}

This agent is a green triarylmethane dye that can also be used to stain the anterior surface of the eye (Fig. 2). This agent is available on a swab moistened with saline for application into the lower fornix. While fluorescein stains between cells to achieve clearer staining of the cornea, lissamine green stains the cells themselves resulting in a complementary effect [13]. Uniquely, lissamine green has not been shown to stain healthy cells and has no toxicity properties [14]. Furthermore, the green coloring of this agent has a greater contrast in the red eye as opposed to the pink hue of rose bengal.

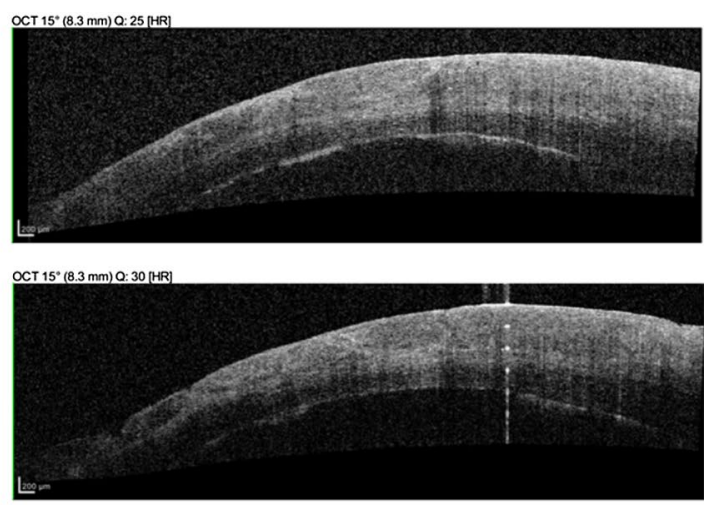

Fig. 1 Fluorescein. A 33-year-old patient suffered a bullet shot across the face. The shearing force resulted in a right eye corneal abrasion. Fluorescein staining was helpful to assess the extent of the epithelial defect. Seidel test was negative and there were no obvious signs of open globe injury. AS-OCT demonstrates areas of epithelial disrup- tion as evidenced by loss of the hyperreflectivity (arrowheads) of the epithelium. There is associated epithelial and stromal edema, and areas of increased stromal hyperreflectivity. Images used in figure taken from authors' unpublished images 
Table 2 Overview of diagnostic staining agents

\begin{tabular}{lll}
\hline Diagnostic agent & Purpose & Other notes \\
\hline Fluorescein & Dye & Available in paper strips or solution with anesthetic \pm preservatives \\
& & $\begin{array}{l}\text { Recommend strips due to less risk of contamination } \\
\text { Various punctate staining patterns suggest different diagnoses } \\
\text { Non-toxic and water-soluble }\end{array}$ \\
Lissamine Green & Dye & Available as strips or 1\% solution \\
& & Stains epithelial cells when mucin coating of cornea is disrupted \\
& Not shown to stain healthy cells \\
& & No toxicity \\
& Recommend in red eyes due to green contrast \\
& More effective \\
Rose Bengal & Available as strips or 1\% solution \\
& Derivative of fluorescein \\
& Stains damaged and healthy cells \\
& May cause patient discomfort upon instillation \\
& Toxic to corneal epithelium
\end{tabular}

\subsubsection{Rose Bengal}

Another stain in the class of organic compounds called xanthenes, rose bengal is also used in eyedrops to stain damaged corneal and conjunctival cells to identify eye damage. Although rose bengal is actually a derivative of fluorescein, this dye is not as commonly used as fluorescein or lissamine green. Rose bengal stains not only dead or damaged cells, but also stains healthy cells [15]. Research shows that tear-film components like mucins, albumin, or even artificial tears can block rose bengal from staining the ocular surface [13].

Furthermore, rose bengal has an intrinsic cellular and dose-dependent toxic effect on corneal epithelial cells that is enhanced by exposure to light, which may hinder diagnosis of a disease [14] Compared to fluorescein and lissamine green, rose bengal causes more patient discomfort due to stinging upon instillation [16].

\section{Cycloplegic/Pain Control Agents}

Agents in this category paralyze the iris sphincter and cause mydriasis or dilation of the pupil (Table 3). Cholinergic-blocking drugs not only induce mydriasis but also paralysis of the ciliary body (cycloplegia). This latter effect paralyzes the patient's ability to focus or accommodate, causing near vision to be blurry until the drug's effect wears off. Thus, while these agents are effective for ciliary pain, patients should be counseled about the shortterm loss of near vision while using these medications.

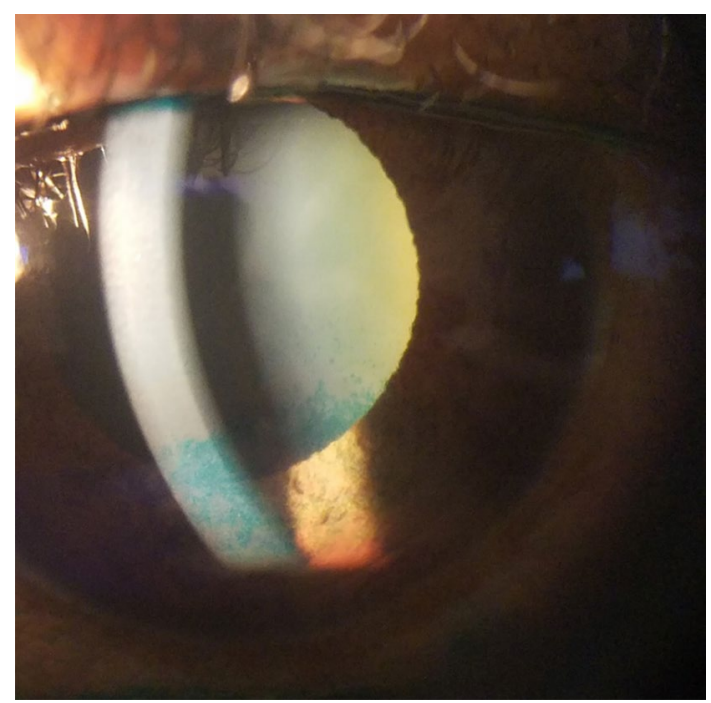

Fig. 2 Lissamine green. Lissamine green can be used to assess for corneal injury, such as punctate epithelial erosions. In this patient, lissamine green highlights areas in the inferior cornea, whereas the superior cornea is relatively unaffected. This type of staining pattern is common in patients with exposure keratopathy or eyelid injuries in which the lower half of the cornea is relatively more exposed to the environment as compared to the superior cornea which is covered by the upper eyelid. Image used in figure taken from authors' unpublished images

\subsection{Atropine Sulfate}

This agent is formulated with either $0.5 \%$ or $1 \%$ concentration. It is one of the strongest cycloplegic drugs available and exerts significant inhibition on the muscarinic 
action of acetylcholine. This is a longer-acting cycloplegic and thus not the ideal agent to dilate the pupil for diagnostic purposes. However, atropine should be considered for treatment of ciliary pain associated with significant intraocular inflammation, as in addition to its analgesic effects, it helps to prevent formation of posterior synechiae between the iris and crystalline lens. Unwanted side effects may last 1-2 weeks. Recently, this medication has gained significant interest in its potential role in the treatment of myopia progression in children [17-19].

\subsection{Homatropine}

Usually formulated with 5\% concentration, this drug can relieve both pain and discomfort of most non-penetrating ocular injuries by relaxing the iris and ciliary body. Homatropine directly blocks muscarinic action of acetylcholine and exerts its effects for a slightly lesser duration as compared to atropine. Homatropine may be preferred to atropine due to a more rapid and shorter duration of action [20].

\subsection{Cyclopentolate}

This agent is formulated with $0.5 \%, 1 \%$, or $2 \%$ concentration. Cyclomydril, a combination drop of cyclopentolate $0.2 \%$ and phenylephrine $1 \%$, is ideal in infants and young children because it produces more complete cycloplegia with a single drop. This is particularly useful in children as they have stronger accommodation capabilities compared to adult patients, thereby necessitating more adequate paralysis of the ciliary muscle. Although systemic absorption is typically minimal, there are case reports of this agent inducing paralytic ileus, bradycardia, and oxygen desaturation in premature and neonatal infants [21, 22]. In pediatric patients, neurotoxic effects may occur, causing symptoms ranging from hallucination, psychosis, seizures, to other acute CNS manifestations [23].

\subsection{Tropicamide}

An antimuscarinic drug producing pupil dilation and cycloplegia, tropicamide is also used to better examine the lens, vitreous, and retina. It is available in two formulations, $0.5 \%$ and $1.0 \%$; the latter is more commonly used. Lasting around 4-10 h, this agent is typically used during dilated fundus examinations and can also be used to break synechiae or adhesions in the eye due to inflammation. In the USA, this agent is often paired with the sympathomimetic drop phenylephrine hydrochloride at $2.5 \%$ concentration. When $0.5 \%$ tropicamide is paired with 5\% epinephrine eyedrops, a study found that premature infants undergoing screening for retinopathy of prematurity achieved twice the dilated pupil surface area with the combination of drugs compared to $0.5 \%$ tropicamide alone [24]. Like other agents in its class, this agent can blur vision and in rare cases cause an attack of acute angle-closure glaucoma so angle-closure risk must be assessed prior to instillation.

\subsection{Scopolamine}

An anticholinergic drug that is more formally used to treat motion sickness and postoperative nausea and vomiting, this medication also affects the eye via pupil dilation and can cause blurry vision as a side effect. A review of the agent noted a clinical trial regarding systemic absorption of ocular scopolamine at $0.25 \%$ concentration and found that the agent was rapidly and efficiently absorbed without affecting patients' blood pressure or heart rate compared to placebo [25]. Like the other anticholinergic drugs, scopolamine works by blocking acetylcholine on eye muscles causing these muscles to relax, which decreases ocular pain and also widens the pupil causing the lens to temporarily lose ability to focus.

Table 3 Overview of cycloplegic agents regarding the onset of action, duration of action and other notes

\begin{tabular}{llll}
\hline Cycloplegic agent & Onset & Duration & Other notes \\
\hline Atropine & $10-15$ min, maximal effect in 30-40 minutes & $3-7$ days & Not recommended for children $<3$ months \\
Homatropine & $15 \mathrm{~min}$, maximal effect in 30-40 min & $1-2$ days & Not recommended for children $<3$ months \\
Cyclopentolate & $20-30 \mathrm{~min}$, maximal effect in $60 \mathrm{~min}$ & $8 \mathrm{~h}$ & Not recommended for children $<3$ months \\
Tropicamide & $15-20 \mathrm{~min}$ & $4-10 \mathrm{~h}$ & $\begin{array}{c}0.5 \% \text { tropicamide with } 5 \% \text { epinephrine } \\
\text { is a safe and effective agent for infant } \\
\text { patients }\end{array}$ \\
& & & Not recommended for children $<3$ months \\
Scopolamine & Rapid, maximal effect within $8 \mathrm{~min}$ & $3-7$ days &
\end{tabular}




\section{Anti-Inflammatory Agents}

\subsection{Anti-Inflammatory Agents: Steroid Medications}

This class of drugs is indicated for treatment of postoperative intraocular inflammation and for pain management. Corticosteroids are potent anti-inflammatory drugs used for the treatment of intraocular inflammation due to their ability to inhibit production of various inflammation-causing mediators (Table 4) [26, 27]. However, many practitioners utilize topical steroids for the treatment of ocular inflammation secondary to traumatic injury, especially when potentially concurrent infectious etiologies have been ruled out and/or adequately treated. Even among ophthalmologists, the use of topical steroids in the presence of corneal infection, with regard to optimal timing and dosing, is very controversial [28]. In select cases, injectable steroids (dexamethasone and triamcinolone), oral steroids (prednisone), and intravenous steroids may be given at the discretion of the clinician. This section will primarily cover topical steroids, and readers are encouraged to consult other resources for information regarding injectable and systemic steroids.

Notable side effects of steroids are accelerated development of posterior subcapsular cataracts and increased intraocular pressure (IOP). Furthermore, steroids can delay corneal wound healing and can worsen herpes simplex virus (HSV) keratitis, bacterial keratitis, and fungal keratitis [22]. Practitioners unfamiliar with ocular injuries should exercise extreme caution prior to dispensing ophthalmic steroids; referral to eye-care practitioners is warranted in most cases.

Finally, topical ophthalmic steroids must be tapered carefully in order to prevent rebound inflammation. Patients should be counseled and educated regarding individual tapering schedules.

\subsubsection{Prednisolone Acetate (0.125\% and $1 \%)$ and Prednisolone Phosphate 1\%}

Prednisolone is a ketone-based steroid. Prednisolone acetate $1 \%$ is among the most commonly utilized topical steroids among eye-care practitioners due its potent anti-inflammatory effects, long-term track record, and financial cost. As this drug is formulated in a suspension, it is important for practitioners to educate patients regarding the importance of adequate "shaking" of the bottle prior to instillation. Previous studies have reported an ideal "shake amount" of approximately 16-20 shakes prior to instilling the medication, with more than $60 \%$ of subjects failing to properly shake the bottle [29]. Prednisolone acetate is also available as a $0.125 \%$ formulation (Pred Mild, Novartis).

Prednisolone phosphate $1 \%$ is formulated as a solution and does not require shaking. However, it exerts significantly less anti-inflammatory effects when compared to prednisolone acetate $1 \%$. Some practitioners prefer this medication when ocular surface inflammation requires primary treatment, and intraocular inflammation is minimally present.

Both prednisolone acetate $0.125 \%$ and prednisolone phosphate $1 \%$ may be favorable for the treatment of mild ocular

Table 4 Overview of topical steroids regarding available formulations, in vitro relative potency, in vivo relative anti-inflammatory activity and other notes

\begin{tabular}{|c|c|c|c|c|}
\hline Steroidal agent & Formulation & $\begin{array}{l}\text { In vitro relative } \\
\text { potency }[26, \\
27]\end{array}$ & $\begin{array}{l}\text { In vivo relative } \\
\text { anti- inflammatory } \\
\text { activity }\end{array}$ & Other notes \\
\hline Prednisolone acetate & $0.125 \%, 1 \%$ suspension & 600 & 4 & $\begin{array}{l}\text { Requires } 16-20 \text { shakes prior to instil- } \\
\text { lation }\end{array}$ \\
\hline Prednisolone phosphate & $1 \%$ solution & 600 & 4 & Solution does not require shaking \\
\hline Loteprednol & $\begin{array}{l}0.2 \%, 0.25 \%, 0.5 \%, 1 \% \text { suspension } \\
0.38 \% \text { gel } \\
0.5 \% \text { ointment }\end{array}$ & 550 & 25 & $\begin{array}{l}\text { Shorter duration of effect, with fewer } \\
\text { adverse reactions }\end{array}$ \\
\hline Difluprednate & $0.05 \%$ emulsion & 1,800 & 60 & $\begin{array}{l}\text { High propensity to elevated IOP } 2 \text { nd line } \\
\text { agent for recalcitrant ocular inflam- } \\
\text { mation }\end{array}$ \\
\hline Fluorometholone & $0.1 \%, 0.25 \%$ suspension & 350 & 40 & $\begin{array}{l}\text { Acetate base offers greater penetration } \\
\text { than alcohol formulation }\end{array}$ \\
\hline Rimexolone & $1 \%$ suspension & 300 & 25 & $\begin{array}{l}\text { Requires IOP monitoring in pediatric } \\
\text { patients }\end{array}$ \\
\hline Dexamethasone & $0.1 \%$ solution & 400 & 25 & Poor ocular penetration \\
\hline Hydrocortisone & $1 \%, 2.5 \%$ ointment & $\mathrm{n} / \mathrm{a}$ & $\mathrm{n} / \mathrm{a}$ & \\
\hline Methylprednisolone & Requires compounding pharmacy & $\mathrm{n} / \mathrm{a}$ & $\mathrm{n} / \mathrm{a}$ & \\
\hline
\end{tabular}

IOP intraocular pressure 
inflammation, especially in patients with pre-existing glaucoma and steroid-responders.

\subsubsection{Loteprednol}

These agents are ester-based steroids in which the position 20 ester group replaces the ketone group of prednisolone acetate [30]. Due to effects of local esterases, loteprednol undergoes degradation into an inactive metabolite after a shorter duration of effect [31]. Therefore, in comparison to prednisolone, loteprednol has lower likelihood of causing unwanted side effects such as posterior subcapsular cataracts and increased IOP [22]. A number of formulations are available, including Lotemax $0.5 \%$ suspension, $0.38 \%$ gel, and $0.5 \%$ ointment (Bausch and Lomb); Inveltys $1 \%$ suspension and Eysuvis $0.25 \%$ suspension (Kala Pharmaceuticals); and Alrex 0.2\% suspension (Bausch and Lomb). While the suspension formulations require shaking, gel formulations do not require shaking, offer superior viscosity, and maintain duration of effect [29].

Zylet, which is a combination of loteprednol $0.5 \%$ suspension and tobramycin, is another popularly used medication for the treatment of concurrent ocular inflammation with minimal infection.

The trade name Lotemax is available as a suspension, gel, and ointment. The trade name Alrex is a suspension available in $0.2 \%$ concentration and thus needs to be shaken. The gel formulation is available as a $0.5 \%$ concentration and does not require shaking. The ointment formulation is a preservative-free preparation indicated for post-operative eye care.

\subsubsection{Difluprednate}

This drug is formulated as an emulsion at $0.05 \%$ concentration and does not require shaking prior to instillation. Compared to prednisolone formulations, this agent has a longer duration of action and more potency as compared to prednisolone acetate $1 \%$ for treatment of intraocular inflammation. This permits less frequent dosing with non-inferior efficacy [32]. It should be noted that the majority of studies that have assessed the efficacy and safety of this agent have primarily been in the setting of endogenous uveitis and post-surgical inflammation. Reports in the literature regarding its efficacy in the setting of corneal injury are extremely limited. Nonetheless, many practitioners utilize this medication for control of severe inflammation or for recrudescent disease.

Multiple case reports have noted that this medication can cause a significant elevation in IOP that may be higher than other topical steroids, especially in pediatric patients $[32,33]$. There is additionally a significant financial cost to obtain this medication.

\subsubsection{Fluorometholone $0.1 \%$}

Fluorometholone is a glucocorticoid with similar potency, decreased intraocular penetration, and side-effect profile as loteprednol. This medication is available in a variety of formulations, including suspensions and ointments.

Among suspensions, available options include fluorometholone alcohol 0.1\% (FML, Allergan; Fluor-Op, Novartis) and fluorometholone with acetate base (Flarex, Alcon Laboratories, Inc, and fFlone, Novartis). The acetate base offers better penetration as compared to the alcohol formulation [34]. Although this agent has less tendency to increase IOP than other ketone-based steroids, ester-based loteprednol may be a better long-term option.

Fluorometholone is also available in a $0.25 \%$ concentration (FML Forte, Allergan) and an ophthalmic ointment.

\subsubsection{Rimexolone}

Formulated as $1 \%$ concentration, rimexolone (Vexol; Alcon Laboratories, Inc.) is a glucocorticoid steroid approved for the treatment of postoperative inflammation after ocular surgery. This agent has garnered interest as it exerts similar anti-inflammatory effects as prednisolone acetate, but has an IOP response rate similar to fluorometholone [35]. A clinical trial concluded that rimexolone seems to be a more effective anti-inflammatory agent compared to fluorometholone and prednisolone acetate 1\% [36]. However, it is suggested to monitor the IOP regularly in the pediatric population when using this agent due to a higher ocular-hypertensive effect compared to adults [35] .

\subsubsection{Dexamethasone}

Dexamethasone, a ketone-based steroid suspension, has poor penetration into the eye and thus may not be an ideal agent for the treatment of ocular inflammation. However, it effectively treats surface inflammation. It is commonly used as an injectable medication. Among ophthalmic steroids, dexamethasone has an extremely high propensity to increase IOP [37] .

\subsubsection{Hydrocortisone}

Hydrocortisone is primarily used in ointment formulation for topical use. It is commonly available in combination with antibiotics, such as neomycin and polymyxin B (Maxitrol, Bausch and Lomb), and used by practitioners for treatment of ocular injury, especially when combined with patching postoperatively. As a single agent, data are limited regarding its efficacy in the ophthalmic literature. One 
study evaluating 411 patients with both hydrocortisone acetate $2.5 \%$ and hydrocortisone acetate $1 \%$ eye ointments reported that both formulations are efficacious and safe treatments for acute inflammation of the ocular surface or adnexa [38].

\subsubsection{Preservative-Free Methylprednisolone}

Short-term use (off-label) of topical corticosteroids can aid in symptomatic dry eye patients with recalcitrant and refractory ocular surface disease, whether as a direct result or sequela of ocular injury. Preparation of this medication typically requires the use of specialty and/or compounding pharmacies, and is therefore ideally best suited for refractory and/or severe pathology. A study on 105 eyes showed that topical use of preservative-free methylprednisolone can be used in pulse therapy for long-term treatment of dry eye in keratoconjunctivitis sicca (KCS) patients with Sjögren's syndrome [39]. Furthermore, there were no serious complications including IOP elevation or cataract formation in the follow-up period. Compared to preserved prednisolone, the non-preservative drops exhibited a lower ocular surface toxicity profile and milder subjective discomfort [40]. Reports in the literature regarding utilization of this medication in the setting of ocular injuries is extremely limited.

\subsection{Anti-Inflammatory Agents: Non-Steroidal Medications}

Non-steroidal anti-inflammatory drugs (NSAIDs) are used for the treatment of ocular inflammation and pain, either as standalone agents or in combination with steroid medications (Table 5). The primary mechanism of action is the inhibition of the cyclooxygenase (COX) enzyme to block the conversion of arachidonic acid into prostaglandins. NSAIDs have also been shown to prevent long-term unwanted sequelae of prolonged intraocular inflammation, such as cystoid macular edema (CME) [41]. However, the routine use of perioperative NSAIDs continues to be a source of debate in the ophthalmic literature.

Desired qualities of topical NSAIDs include effective anti-inflammatory capabilities, rapid onset of action to reduce ocular inflammation, acceptable safety profile and convenient dosing regimen [42]. NSAID molecules have poor intraocular penetration and thus require alteration in order to increase their bioavailability [43]. Since these medications are primarily weakly acidic, the $\mathrm{pH}$ must be raised in order to increase the unionized fraction of the drug to improve corneal penetration. Another approach is to increase halogenation of NSAIDs to improve potency and increase corneal penetration [44]. Additionally, while preservatives such as benzalkonium chloride (BAK) are often added to augment ocular penetration, this increases ocular surface toxicity [45]. Thus, the use of topical NSAIDs for reasonable time lengths (between 2 and 6 weeks) appears safe with proper monitoring for side effects. These agents must be used cautiously due to potential for corneal toxicity and melting [46, 47]. In addition, there have been recent reports that have noted increased ocular bleeding, including hyphema, associated with topical NSAIDs after ocular surgery [48].

Overall, practitioners may choose from several readily available medications. While dosing regimens and patientincurred costs may vary, there are no clear guidelines regarding the superiority or preferred practice patterns of one agent over another.

Table 5 Overview of non-steroidal anti-inflammatory agents regarding bottle sizes, dosing and other notes

\begin{tabular}{|c|c|c|c|}
\hline NSAID & Bottle size & Dosing & Other notes \\
\hline Ketorolac Tromethamine $0.4-0.5 \%$ & $5 \mathrm{ml}$ & QID & $\begin{array}{l}\text { Pediatric use at } 3 \text { years } \\
\text { Available in preservative-free formulation (Acuvail, } 0.45 \% \text { ) } \\
\text { Associated with corneal ulceration when used on compromised and neurotrophic } \\
\text { ocular surface }\end{array}$ \\
\hline Diclofenac sodium $0.1 \%$ & $2.5 \mathrm{ml}, 5 \mathrm{ml}$ & QID & $\begin{array}{l}\text { Compared to Ketorolac, may have more pronounced and longer lasting effects in } \\
\text { regards to corneal sensitivity }\end{array}$ \\
\hline Nepafenac $0.1 \%$ & $3 \mathrm{ml}$ & TID & $\begin{array}{l}\text { Pediatric use at } 10 \text { years } \\
\text { Must be shaken before instillation } \\
\text { Prodrug which is converted to amfenac by corneal esterases }\end{array}$ \\
\hline Nepafenac $0.3 \%$ & $1.7 \mathrm{ml}$ & QD & $\begin{array}{l}\text { Pediatric use at } 10 \text { years } \\
\text { Must be shaken before instillation }\end{array}$ \\
\hline Bromfenac $0.075 \%$ & $5 \mathrm{ml}$ & $\mathrm{n} / \mathrm{a}$ & $\begin{array}{l}\text { Do not use in sulfite allergy } \\
\text { Not a prodrug }\end{array}$ \\
\hline
\end{tabular}




\subsubsection{Ketorolac Tromethamine $0.4-0.5 \%$}

Due to the addition of tromethamine to increase corneal permeability, ketorolac has significant side effects of ocular surface irritation. Modifications of this agent include decreasing the concentration of the solution, adding a phosphate buffer to the formulation, and/or varying the $\mathrm{pH}$ level [49]. Ketorolac is also available in a preservative-free formulation (Acuvail, $0.45 \%$ ), which may be useful in patients with corneal injury.

\subsubsection{Diclofenac Sodium 0.1\%}

Diclofenac is usually available in the sodium salt form as this form has been found to have increased solubility [50].

Both ketorolac and diclofenac have been the historical benchmark for topical NSAIDs. With regard to corneal sensitivity, a head-to-head study found that both agents decreased corneal sensitivity significantly but were more pronounced and longer lasting with diclofenac [51, 52]. Both drugs are well tolerated and useful for pain reduction postrefractive corneal surgery.

\subsubsection{Nepafenac}

Nepafenac is a prodrug that undergoes enzymatic conversion after corneal penetration into the active compound of amfenac sodium. Available formulations include Ilevro 0.3\% (Alcon Laboratories) and Nevanac 0.1\% (Alcon Laboratories). The higher concentration of the former allows for once-daily dosing compared to the latter. Both medications are suspensions that must be shaken before instillation.

\subsubsection{Bromfenac}

Bromfenac has increased lipophilicity and an additional halogenated bromine moiety to increase lipophilicity and enhance COX inhibition [44]. It is ten times more potent than diclofenac and 18 times more potent than ketorolac [53, 54]. Of note, while bromfenac is an amfenac derivative, it is not a prodrug like nepafenac. As such, this medication does not require enzymatic activation into a metabolically active form in order to exert its therapeutic effect. Clinical data in animal models have shown sustained and detectable drug levels for $24 \mathrm{~h}$ in ocular tissues [55].

In 2009, Xibrom (bromfenac 0.09\%; Bausch and Lomb) was introduced with twice-daily dosing. One year later, Bromday (bromfenac 0.09\%; Bausch and Lomb) was available with the advantage of once-daily dosing. More recently, Prolensa (bromfenac 0.07\%; Bausch and Lomb) has become available with a lower concentration, $\mathrm{pH}$ of 7.8 , and oncedaily dosing. In early 2016, the US Food and Drug Administration (FDA) approved BromSite (Sun Pharmaceuticals) as the first NSAID to prevent ocular pain post-cataract surgery and inflammation. The low concentration of $0.075 \%$ is achieved by its delivery vehicle, which extends the amount of time the drug is on the ocular surface [56].

Of note, any bromfenac formulation should not be used in patients with a sulfite allergy, which is seen more frequently in asthmatic patients.

\subsection{Immunomodulating Agents}

Besides steroids and NSAIDs, several other agents may be used in the management of corneal injuries. This section discusses commonly used immunomodulators that can be used to alter the immune system activity and secondarily decrease ocular inflammation. Practitioners may use these medications as monotherapy agents or in conjunction with previously discussed anti-inflammatory medications. A popularly employed strategy is to combine low-potency topical steroids with an immunomodulatory agent, especially in the treatment of refractory ocular surface disease.

Cyclosporine and lifitegrast are two commonly used topical immunomodulators in ophthalmic practice. To date, there are no comparative trials that assess the superiority of one agent over the other. Clinicians commonly utilize both agents according to clinical experience, type of ocular surface disease, and patient access/health insurance coverage of a given medication. Several compounding pharmacies have also recently introduced cyclosporine formulations.

\subsubsection{Cyclosporine}

Cyclosporine inhibits calcineurin, which is involved in upregulation of various cytokines that activate $\mathrm{T}$ cells. By inhibiting $\mathrm{T}$ cells, topical cyclosporine inhibits ocular surface inflammation and secondarily increases aqueous tear production in patients with aqueous tear deficiency. It is frequently used in the management of ocular surface disease and keratoconjunctivitis sicca when used in a twice-daily dosing regimen.

Several formulations of cyclosporine are commercially available. Restasis ( $0.05 \%$ concentration; Allergan) and Cequa ( $0.09 \%$ concentration; Sun Ophthalmics) are commonly used for treatment of ocular surface disease. Some practitioners may choose to additionally utilize these medications to treat severe dry eye disease that results concurrent with or as a result of corneal injury.

Common side effects include ocular surface irritation, conjunctival hyperemia, and blurred vision. Beneficial effects of this medication may take 3 months to occur, so patients must be counseled regarding expectations and timeframe of effect. 


\subsubsection{Lifitegrast}

Lifitegrast inhibits LFA-1, which is involved, along with its ligand, intercellular adhesion molecule 1 (ICAM-1), in upregulation of lymphocytes, cytokine secretion, cell destruction, and other inflammatory responses that aggravate ocular surface disease [57]. Commercially, this agent is available as Xiidra (Novartis), which is a 5\% concentration solution that can be used in patients with severe and refractory ocular surface disease [58]. In clinical trials, Xiidra improved ocular discomfort and eye dryness compared to placebo when used twice daily over 84 days [59].

Lifitegrast has similar side effects to cyclosporine. Notably, some patients may report a metallic taste after instillation of the medication. Beneficial effects of this medication may take up to 8 weeks to occur.

\section{Oral Agents}

\subsection{Antibiotics (Off-Label Use)}

\subsubsection{Tetracyclines}

Among the tetracyclines, oral doxycycline is an agent of interest among eye-care practitioners in the treatment of ocular surface disease. While at high doses oral doxycycline primarily has an antimicrobial effect, at low doses it can be used as an effective and economical anti-inflammatory with minimal side effects. Specifically, doxycycline is highly effective at inhibiting pro-inflammatory cytokines, including matrix metalloproteinases (e.g., MMP-6 and MMP-9), and inhibiting ocular flora toxic byproducts [60, 61].

With regard to off-label usage, doxycycline is especially effective for the treatment of ocular rosacea and meibomian gland disease, both which may be exacerbated by corneal injury or occur as a result of it. Dosing regimens vary among practitioners, ranging from $20-50 \mathrm{mg}$ once or twice daily to higher doses for recalcitrant disease (100-200 mg once or twice daily). In general, clinicians should strive to use the least amount of this antibiotic in order to still maintain therapeutic effect. A recent Cochrane database review concluded that there was insufficient evidence to draw any meaningful conclusions on the use of oral antibiotics for chronic blepharitis [62].

While a variety of side effects are common to other antibiotics (e.g., nausea, vomiting, etc.), there are several side effects unique to this class of medications that patients should be counseled about. For example, photosensitivity/ skin rash may occur, so patients should be advised to use sun protection and avoid excessive sunlight. Doxycycline is the preferred agent when patients have allergies to penicillin and sulfa drugs.
Minocycline may also be used in a similar manner [63]. Currently, Phase 2 clinical trials regarding the potential role of topical minocycline are being conducted [64].

\subsubsection{Macrolides}

Macrolides are primarily bacteriostatic, time-dependent antibiotics that are used topically for prophylaxis. Erythromycin is the most commonly utilized agent in this class, and is often used for protection of the ocular surface, treatment of corneal epithelial injury, and treatment of ocular surface flora. It is especially effective in pediatric patients due to its low side-effect profile when used topically, particularly in the setting of acute ocular injuries. Unfortunately, because of its long-term use for decades, many bacteria are increasingly resistant to erythromycin so it should not be considered as a therapeutic agent in the setting of active ocular infection. Many practitioners utilize this medication as a lubricating ointment to be used during sleeping in order to prevent deleterious effects of exposure keratopathy in the setting of ocular injuries.

Azithromycin differs from erythromycin by its inclusion of a nitrogen-methyl group in the lactone ring that improves drug stability in acidic environments [65]. It can be used topically or systemically. AzaSite (Inspire Pharmaceuticals) is an ophthalmic solution used for the treatment of bacterial conjunctivitis and blepharitis with low intraocular penetration. Several studies have shown that this agent has prolonged residence time on the ocular surface and requires a less frequent dosing regimen [66]. Collectively, the results of both published and unpublished studies of azithromycin for the treatment of blepharitis suggest significant benefit in the treatment of either posterior blepharitis or mixed anterior-posterior blepharitis [67]. Compared to erythromycin, azithromycin demonstrated superiority in the treatment of chronic mixed anterior blepharitis [68]. Side effects of this medication include potential acute glaucoma and anterior chamber toxicity [69].

Oral azithromycin may also be used as a pulse-dose or low-dose medication for the treatment of ocular surface disease in a similar manner to doxycycline. Given its role in the treatment of community-acquired pneumonias, practitioners may wish to limit the use of oral azithromycin for treatment of ocular diseases when other options have not been utilized.

\subsection{Vitamins}

\subsubsection{Vitamin C}

Corneal wound healing after ocular injury or infection is an intricate and multifactorial process. A significant and potentially vision-limiting component of corneal wound healing is 
the development of corneal haze and scarring secondary to changes in the extracellular matrix and corneal neovascularization [70]. Vitamin C neutralizes oxygen free radicals and inhibits damage to neighboring epithelial and stromal tissues surrounding a wound with protective effects on the cornea. Several studies have demonstrated the importance of vitamin $\mathrm{C}$ in generation of healthy keratocyte tissue, enhancement of collagen synthesis, and suppression of corneal neovascularization [71, 72]. Another proposed mechanism of action is that ascorbic acid accelerates corneal epithelial wound healing by enhancing and upregulating corneal epithelial stem/progenitor cells [73].

A study of 82 eyes affected with infectious keratitis treated with both intravenous and oral vitamin $\mathrm{C}$ found that systemic vitamin $\mathrm{C}$ supplementation reduced corneal opacity size [74]. This finding may be of particular interest to clinicians when treating patients with infectious keratitis in the context of corneal injury. As mentioned previously, the use of corticosteroids continues to be controversial due to concerns in delaying wound healing and prolonging infection [75]. As such, vitamin C supplementation may be an effective means to decrease unwanted corneal opacity without incurring potential side effects of steroids. Furthermore, vitamin $\mathrm{C}$ may additionally be useful in cases of exuberant ocular surface inflammation associated with corneal thinning and risk of perforation, such as may occur in the setting of chemical and/or thermal injury.

\section{Amniotic Membrane Therapies}

Amniotic membrane (AM) has become a popularly used tool in the treatment of ocular surface disease, ocular injuries, neurotrophic disease, and infectious keratitis (Table 6). When used as a mechanical device, as discussed below, the epithelium and stroma possess a number of beneficial cytokines and growth factors [76]. While the exact mechanism of action remains to be elucidated, it is thought that AM serves as a scaffold-like substrate promoting epithelial migration and re-epithelialization. The full discussion of cytokine activity and immune mechanisms is beyond the scope of this article, but has been reported extensively in the literature [77, 78].

AM can be used in eyedrop form or as a mechanical barrier placed on the eye via amniotic membrane transplantation (AMT).

\subsection{Amniotic Membrane Extract (AME) and Amniotic Fluid (AF) Eyedrops}

Amniotic membrane extract (AME) can be used to formulate eyedrops, with or without umbilical cord blood. This combination may be advantageous because the active-matrix component responsible for exerting the antiinflammatory effects of AM (HC-HA/PTX3 complex) is also found in cord blood, which is more effective than AM in inhibiting inflammatory markers [79]. Amniotic fluid (AF) contains a variety of beneficial electrolytes, growth

Table 6 Overview of amniotic membrane therapies (AMTs) regarding their advantages, disadvantages and examples of each therapy

\begin{tabular}{|c|c|c|c|}
\hline AMT & Advantages & Disadvantages & Examples \\
\hline \multirow[t]{2}{*}{ Amniotic membrane extract (AME) } & $\begin{array}{l}\text { Can be used to formulate eyedrops } \pm \\
\text { umbilical cord blood }\end{array}$ & \multirow[t]{4}{*}{$\begin{array}{l}\text { Not approved by US Food and Drug } \\
\text { Administration }\end{array}$} & Regenesol® \\
\hline & $\begin{array}{l}\text { Avoids mechanical placement of amniotic } \\
\text { membrane (AM) tissue }\end{array}$ & & Genesis ACE® \\
\hline Amniotic fluid eyedrops (AF) & $\begin{array}{l}\text { Contains variety of electrolytes, growth } \\
\text { factors and cytokines that help promote } \\
\text { ocular surface healing }\end{array}$ & & \multirow[t]{2}{*}{ Regener-Eyes ${ }^{\circledR}$} \\
\hline & Avoids mechanical placement of AM tissue & & \\
\hline $\begin{array}{l}\text { Cryopreserved } \\
\text { AMT }\end{array}$ & $\begin{array}{l}\text { Cryopreservation better preserves fetal } \\
\text { tissues' structural and biological signaling } \\
\text { molecules } \\
\text { Reduces pain, haze, and inflammation } \\
\text { Can treat moderate dry eye diseases }\end{array}$ & Requires in-office or surgical placement & Prokera ${ }^{\circledR}$ \\
\hline Dehydrated AMT & $\begin{array}{l}\text { Air or heat is used to remove moisture from } \\
\text { AM }\end{array}$ & $\begin{array}{l}\text { Requires in-office or surgical placement } \\
\text { and requires additional placement of } \\
\text { bandage contact lens with use of topical } \\
\text { antibiotic drops }\end{array}$ & $\begin{array}{l}\text { AmbioDisk }{ }^{\circledR} \\
\text { Aril }{ }^{\circledR} \\
\text { Sursight }{ }^{\circledR} \\
\text { Eclipse } \circledR\end{array}$ \\
\hline
\end{tabular}


factors, and cytokines that help promote ocular surface healing [80].

While several of these products are available in the USA, it is important to note that none of these products, at the time of writing, are approved by the FDA. Regenesol (Biotissue/Tissue Tech Inc., Miami, FL, USA) is an AME combined with cord blood. Genesis ACE (Ocular Science Inc.; Manhattan Beach, CA, USA) is a cryopreserved AM drop that can be used twice daily. Finally, Regener-Eyes (Regener-Eyes; Palm Beach, FL, USA) is an AF eyedrop that can be used one to four times daily.

A major advantage of AME and AF eyedrops is to avoid mechanical placement of AM tissue (as discussed in the next section) and its associated complications. When prepared from fresh tissue, these eyedrops may contain epithelial cells that may help in regeneration as stem cells [81]. These eyedrops may be used in conjunction with AM placement for severe cases. This is an area of significant research interest and it remains to be seen how effective $\mathrm{AME}$ and AF eyedrops can be in the future, especially in comparison to currently existing therapies.

\subsection{Cryopreserved Amniotic Membrane Transplantation (Cryopreserved AMT)}

Cryopreservation is the most common preservation technique for amniotic membranes. Compared to the dehydrated AMT, cryopreservation better preserves the fetal tissues' structural and biological signaling molecules [82]. Prokera (BioTissue) is a temporary and sutureless AMT that allows for easy insertion and replacement in the office. This therapy reduces pain, haze, and inflammation associated with severe bacterial keratitis and other ocular surface disease states [83]. Although limited use of cryopreserved AMT is a safe and effective way to promote healing of the ocular surface, recurrence of underlying primary pathology is a concern [84]. Furthermore, cryopreserved AMT can be used to treat moderate dry eye diseases, even generating improvement in the contralateral eyes [85]. However, there may be more pain associated with cryopreserved products due to presence of a symblepharon ring in this form of AMT.

When used judiciously, cryopreserved AMT can be extremely beneficial for the treatment of severe ocular surface disease and injury. However, it is the authors' opinion that AMT has recently been overutilized and misused in the treatment of ocular injuries, potentially due to its favorable reimbursement schedule.

\subsection{Dehydrated Amniotic Membrane Transplantation (Dehydrated AMT)}

Air or heat is used to remove moisture from the amniotic membrane and gamma irradiation is used to sterilize the tissue [86]. A study on nine eyes found that sutureless dehydrated AMT achieved resolution of persistent epithelial defects secondary to various etiologies in $89 \%$ of the eyes with significant improvement in vision [87]. There are a variety of dehydrated AMT products available, such as AmbioDisk (Katena), Aril (Seed Biotech), Sursight (Surgenex), and Eclipse (Ophthalogix). One advantage of dehydrated AMT products, such as AmbioDisk, is that they include retention of all three layers of the AM, including the intermediate layer, which possesses additional beneficial growth factors [88]. In addition, the absence of a symblepharon ring may make these products more tolerable on the ocular surface, especially in the setting of an already inflamed and painful eye. Finally, it should be noted that dehydrated AMT requires an additional placement of a bandage contact lens with use of topical antibiotic drops for infection prophylaxis.

\section{Blood-Based Therapies}

A significant number of peer-reviewed papers involving blood-derived eyedrops have been published recently showing the expanded indication for treatment, including ocular surface disease, persistent epithelial defects, neurotrophic corneal disease, and limbal stem cell disease (Table 7) [89, 90]. However, there are still several issues under debate related both to the lack of a standardized protocol for preparation and storage, and to the absence of clinical consensus regarding strategies for clinical outcomes, patients' stratification, length of treatment, and the rationale for repeated treatments. In the USA, blood and blood products are under the surveillance of the FDA [91] .

\subsection{Autologous Serum Tears}

Serum obtained by blood draw is a commonly used product for the formulation of eyedrops. The benefits of autologous serum tears (ASTs) may be due to their similar composition to tears and various epitheliotrophic growth factors [92]. Patients' serum is usually with a salt solution, preservative-free normal saline, or another sterile, preservative-free, eye-compatible solution at appropriate concentration $(20-100 \%)$ in order to produce autologous serum tears (ASTs) [93]. Studies have shown that although ASTs may be effective in treating persistent epithelial defects and severe dry eye with few adverse effects [94-97]. Despite several clinical trials showing the safety and efficacy of ASTs, a recent Cochrane meta-analysis 
Table 7 Overview of blood-based therapies and notable advantages and disadvantages

\begin{tabular}{|c|c|c|}
\hline Blood-based therapies & Advantages & Disadvantages \\
\hline Autologous serum tears (ASTs) & $\begin{array}{l}\text { Similar composition tears } \\
\text { Effective in treating persistent epithelial } \\
\text { defects and severe dry eye } \\
\text { Concentrations ranging from } 20-90 \% \text { can be } \\
\text { used depending on severity of ocular surface } \\
\text { disease }\end{array}$ & $\begin{array}{l}\text { Requires patient blood drawn } \\
\text { Patient's blood may contain unwanted autoan- } \\
\text { tibodies or cytokines precluding effective } \\
\text { use }\end{array}$ \\
\hline $\begin{array}{l}\text { Allogenic peripheral blood serum tears (APB- } \\
\text { STs) }\end{array}$ & Works around the disadvantages of ASTs & $\begin{array}{l}\text { Requires } \mathrm{ABO} \text { antigen matching between } \\
\text { donors and recipients } \\
\text { Requires infection surveillance }\end{array}$ \\
\hline $\begin{array}{l}\text { Allogenic umbilical cord blood serum tears } \\
\text { (AUCBSTs) }\end{array}$ & $\begin{array}{l}\text { Higher concentration of multiple growth } \\
\text { factors compared to other blood derived } \\
\text { products }\end{array}$ & $\begin{array}{l}\text { Needs to be obtained from umbilical cord } \\
\text { serum at time of delivery }\end{array}$ \\
\hline Platelet-derived tears (PDTs) & $\begin{array}{l}\text { Includes platelet-rich plasma (PRP) tears and } \\
\text { plasma-enriched growth factors (PRGF) tears } \\
\text { Both allogenic and autologous sources can be } \\
\text { used } \\
\text { Compared to ASTs, PRGF eyedrops exert bet- } \\
\text { ter wound healing } \\
\text { May benefit patients suffering from autoim- } \\
\text { mune diseases } \\
\text { Clinicians are able to make tears in office }\end{array}$ & \\
\hline Finger-prick autologous blood (FAB) & Cheaper and more convenient & \\
\hline
\end{tabular}

failed to show significant results owing to low evidence [98]. ASTs can be dosed four to six times a day. Nevertheless, many practitioners employ the use of ASTs for the treatment of recalcitrant ocular surface disease, including variants that demonstrate limbal pathology [99] or associated with systemic chemotherapy toxicity [100]. Additionally, randomized controlled trials have concluded that serum therapy aids in faster re-epithelialization of postkeratoplasty epithelial defects compared to artificial tears [101, 102].

\subsection{Allogenic Peripheral Blood Serum Tears}

In some cases, patients may not be able to safely have blood drawn or there may be an unwanted number of serum-derived autoantibodies or pro-inflammatory cytokines present in the blood of patients with inflammatory comorbidities, precluding the effective use of ASTs. There is increasing interest in the use of allogenic donors for the production of allogenic peripheral blood serum tears (APBSTs) [103]. APBST production remains a challenge to ensure hemato-immunological ABO antigen matching between donors and recipients. Infection surveillance, similar to other transfused blood products, is another important consideration that may restrict the use of APBSTs to select patient populations.

\subsection{Allogenic Umbilical Cord Blood Serum Tears}

Allogenic umbilical cord blood serum tears (AUCBSTs) can be obtained from umbilical cord serum taken at the time of delivery. Similar infectious surveillance to that described with APBSTs must be undertaken. AUCBSTs have a higher concentration of multiple growth factors compared to other blood-derived products, though notably have a lower level of IGF-1 and vitamin A when compared to APBSTs [104].

\subsection{Platelet-Derived Tears}

Platelet-derived tears (PDTs) include several variants, including platelet-rich plasma (PRP) tears and plasmaenriched growth factors (PRGF) tears. PDTs have an extremely favorable concentration of growth factors and cytokines [105]. Both allogenic and autologous sources can be used, though the latter is preferred, whenever possible, due to factors discussed previously.

Plasma-enriched growth factor (PRGF) eyedrops are similarly derived from a patient's own blood with several notable differences. First, PRGF eyedrops include a patient's plasma, as well as a high concentration of platelets, as compared to ASTs. Studies have suggested that PRGF eyedrops exert better wound healing on the ocular surface compared to ASTs [106, 107]. Through more potent regenerative and anti-inflammatory effects, PGRF eyedrops minimize scar formation compared to ASTs and could be a 
safe and effective treatment option for refractory ocular surface lesions [108]. A newer type of PRGF eyedrop therapy involves heat inactivation, which increases proliferation and migration of ocular surface cells. A study has found that heat-inactivated PGRF eyedrops reduce complement activity and decrease $\operatorname{IgE}$ while still maintaining the biological activity of PGRF, which may benefit patients suffering from autoimmune diseases [109].

One key advantage of PRGF is clinicians' ability to make the tears in-office (Endoret kit; BTI Biotechnology, Institute, Spain) rather than relying on the use of specialty blood banks and/or compounding pharmacies.

\subsection{Finger-Prick Autologous Blood}

Compared to the other blood products, finger-prick autologous blood (FAB) uses whole capillary blood and is a cheaper and more convenient alternative. A report studying ten eyes found that FAB therapy alongside conventional treatment successfully managed refractory persistent epithelial defects without adverse effects [110]. Furthermore, FAB therapy was shown to be safe and effective in the treatment of dry eye syndrome in 29 eyes [111]. Although not autologous, a case study found that even maternal allogenic blood was successful in closing an epithelial defect without immunological reaction [112].

\section{Mechanical Barrier Therapies}

\subsection{Bandage Contact Lenses}

Studies have found that bandage contact lenses (BCLs) are effective in reducing pain from traumatic abrasions with the added advantage of maintaining vision during treatment $[113,114]$. BCLs may be used alone or in conjunction with AM placement to facilitate wound healing. Often, a soft contact lens is used, although other lens types can be considered such as scleral and semi-scleral lenses if the soft contact lens is unable to heal the defect $[115,116]$. The lens can be left for 2 weeks to 1 month depending on the recommended wearing modality of the lens. Topical antibiotics should be strongly considered in the presence of epithelial defects in order to prevent secondary infections. Topical steroids should never be used alone when a BCL is used, unless topical antibiotics are concurrently administered.

\subsection{Nonbiologic Glue: Cyanoacrylate}

In cases of impending perforations, minor perforations, corneal melts, and wound leaks, cyanoacrylate glue can be used as a corneal patch. Several studies have found cyanoacrylate, especially variants with moderate-length alkyl side chains, to be effective in the treatment of corneal perforation [117-119]. While cyanoacrylate glue prevents epithelialization in the area of the damaged cornea, it also prevents the activation of collagenases and other enzymes involved in stromal melting. Furthermore, cyanoacrylate glue itself possesses a bacteriostatic property with a favorable profile against Gram-positive organisms. It should be noted that use of this adhesive product is considered an off-label use of the medications.

Cyanoacrylate glue can be placed in the office setting with local anesthesia. Care should be undertaken to ensure no glue enters the anterior chamber, and only the necessary amount should be used to cover the defect in order to avoid inadvertently spreading onto the ocular surface. A variety of application techniques have been described [120-122]. A BCL can additionally be placed over the glue for patient comfort, and topical antibiotics should be given along with consideration for other anti-inflammatory medications, such as systemic doxycycline and vitamin $\mathrm{C}$ supplementation. Topical steroids should again be used judiciously, if at all, in such cases.

A robust amount of corneal neovascularization and scarring is expected in the area underneath and adjacent to the glue. In most cases, the glue may fall off spontaneously or be removed at the discretion of the clinician.

\subsection{Biologic Glue: Fibrin Glue}

The first commercially available fibrin sealant (Tisseel, Baxter) was reported to be useful for the treatment of corneal perforations in 2001 [123]. Fibrin sealants consist of a thick component (fibrinogen) and thin component (thrombin) that can be mixed together to form a biologic sealant. A variety of techniques have been described, including with and without AMT placement and BCL use.

Compared to cyanoacrylate, fibrin glue may be less toxic but not as readily available [120]. Furthermore, a study found fibrin glue to be easier to use than cyanoacrylate glue due to less crust formation on the corneal surface, which can be irritating to the patient [124]. However, fibrin glue requires a significantly longer time for adhesive plug formation compared to cyanoacrylate adhesive [125]. Although cyanoacrylate-based glues have traditionally been the most widely used glue, the literature supports fibrin glue as an effective substitute for attaching biologic tissues and as surface sealants [126].

\subsection{Tarsorrhaphy}

This procedure involves placement of temporary or permanent sutures between the upper and lower eyelid together to facilitate corneal healing and protect a neuropathic (anesthetic) cornea that is at risk for damage and infection. 
The amount of tarsorrhaphy ranges from 20 to $90 \%$ of the eyelid margin, and is left to the discretion of the clinician. Tarsorrhaphy and bandage contact lenses are conventional treatment options for refractory neurotrophic corneal ulcers [127]. This procedure can similarly be combined with other therapies, such as AMT placement. Compared to patching the eye, lateral tarsorrhaphy (suturing the free outer edge of the eyelids together) provided quick relief and more rapid corneal epithelial defect healing in a study involving 36 patients [128]. Tarsorrhaphy is generally safe, can be performed quickly in the office setting, and is remarkably effective in managing non-healing and persistent epithelial defects with minimal complications. It is suggested to perform this procedure sooner rather than later when persistent epithelial defects do not respond to medical therapy [128]. Drawbacks of this technique include patient complaints due to comfort and cosmesis, and difficulty in examination of the ocular surface in cases of large tarsorrhaphies.

\section{Novel Agents}

A number of novel agents have recently been introduced or are undergoing late-phase clinical trials that are of significant interest to both researchers and clinicians treating ocular injuries (Table 8).

\subsection{Recombinant Human Nerve Growth Factor: Cenegermin}

Cenegermin at $0.002 \%$ concentration is an eyedrop formulation recently approved for moderate to severe neurotrophic keratitis (NK). It is the first FDA-approved medication for the treatment of persistent epithelial defects due to NK in adult patients [129]. After gaining FDA approval in August 2018, this drug became available in the USA in early 2019.

This drug targets nerve pathology and has potential to address the underlying deficit in NK by enhancing corneal nerve growth, restoring corneal sensation, and augmenting corneal healing [130-133]. Clinical trials in NK patients found Cenegermin eyedrops to be safe and effective in restoring corneal integrity, and a randomized control trial found that these drops have higher rates of corneal healing compared to placebo $[134,135]$. Although reported adverse effects with this agent have been minor (most commonly local ocular pain), a recent case report noted corneal epithelial plaque formation associated with Cenegermin that resolved upon cessation of the drug [136]. However, this drug's safety in randomized control trials have been well documented [135, 137].

A disadvantage of Cenegermin is that the formulation is not highly stable. The standard regimen is one drop administered six times per day for 8 weeks. Due to the unstable formulation, Cenegermin must be kept refrigerated and weekly trays are sent to patients along with an accompanying delivery system kit [138].

\subsection{Topical Insulin}

Several studies have found topical insulin to be an effective and simple adjuvant therapy for neurotrophic corneal ulcers, especially when these lesions are non-responsive to standard therapy [139, 140]. In diabetic patients, insulin eyedrops are effective for healing corneal epithelial defects and safe for human ocular use [141].

\subsection{Substance P (FGLM-NH2 Derived)}

Although the current literature on eyedrops containing substance P-derived peptides is limited, a case report of a 16-month-old boy with persistent corneal epithelial defect and NK was treated with both FGLM-NH2 and SSSRderived tetrapeptides with successful resurfacing of the corneal epithelial defect [142]. A clinical trial with 26 eyes with persistent corneal epithelial defects associated with NK were also treated with eyedrops containing FGLM and SSSR peptides, which induced rapid resurfacing of the epithelial defects in stem cell-positive individuals with NK [143].

\subsection{Insulin-Like Growth Factor (SSSR Derived)}

The SSSR sequence mediates the synergistic effect of insulin-like growth factor 1 (IGF-1) with substance P on corneal epithelial wound healing. Local administration of the SSSR tetrapeptide alone or in combination with FGLM amide are potential new strategies for the treatment of persistent epithelial defects [143-145].

\subsection{Metalloproteinase Modulators (Thymosin B4, RGN-259)}

Thymosin beta-4 is a protein and major cellular constituent in tissues that can promote cell migration, formation of blood vessels, and lower pro-inflammatory cytokines [146, 147]. In a study, nine patients with chronic neurotropic persistent epithelial defects were treated with topical thymosin beta-4 with all patients reporting reduced ocular irritation [146]. Patients with geographic defects showed dramatic healing without significant neovascularization.

\subsection{Gap Junction Hemichannel Modulators/ CODA001 (Antisense Nucleotide)}

Nexagon, a connexin 43 antisense gel, is a novel drug that can aid in healing persistent epithelial defects due to ocular burn or chemical injury. Connexin 43 is a protein that comprises 


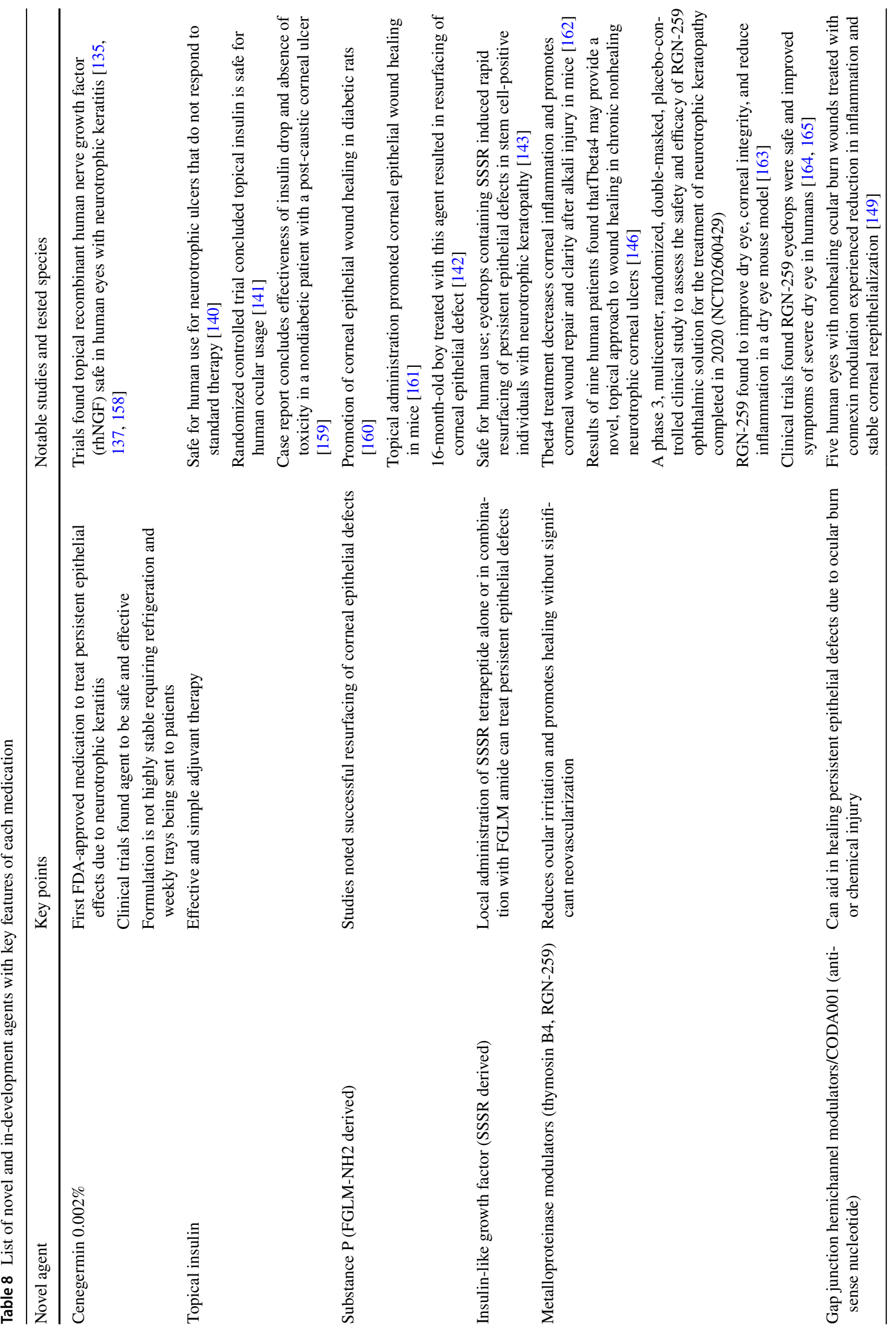


cellular gap junctions that allow for direct communication between cells and transferring of molecules [148]. Results from human trials with Nexagon in nonhealing ocular burn wounds leading to persistent epithelial defects have been encouraging in promoting vascular recovery and decreasing inflammation [149].

\subsection{Matrix Therapy Agent (ReGenerating Agent or RGTA)}

RGTAs are chemically bioengineered and biodegradable polymers that act to mimic the action of heparan sulfate linked to a matrix protein and to growth factors in injured tissue. Extracellular matrix components are trapped within the bioskeleton of RGTA, and due to its special structure, this large molecule only acts on the surface of injured tissue. As a result, the RGTAs promote tissue regeneration and epithelial wound closure $[150,151]$. A study in 11 eyes with severe dystrophic cornea or painful corneal ulcers treated with RGTA ophthalmic solution resulted in significant pain reduction and corneal healing without side effects [152]. Another study also found RGTAs to be a useful, noninvasive approach in NK management with regard to corneal healing [153]. Furthermore, studies of keratoconus patients undergoing cross-linking found that patients receiving RGTAs had significantly faster wound healing $[154,155]$. However, an uncontrolled case series of six eyes with severe corneal neurotrophic ulcers treated with RGTAs found the efficacy of this drug to not match the encouraging results of previous studies [156]. A case report found that the combined use of RGTA and cord blood serum eyedrops successfully treated a large persistent epithelial defect [157]. Combining RGTAs with other therapies could be new potential options for the successful treatment of persistent epithelial defects when just a single drug is not effective.

\section{Conclusion}

Management of corneal injuries/infections can be challenging, depending on the size and extent of damage. Over the years, significant technological and pharmacological advancements have been made that have significantly improved our ability to manage, follow, and treat such injuries. Clinicians may choose from a variety of currently available medications to optimize effective, economical, and efficient treatment of ocular surface injuries.

There are currently a wide array of agents used for analgesic, diagnostic, and therapeutic purposes for management for corneal pain and injury. The recently developed novel agents are an area of significant interest with diverse mechanisms of actions that have shown promising results in both animal models and humans. Cenegermin $0.002 \%$ 
is the first FDA-approved medication to treat neurotrophic keratitis with an excellent safety profile. In addition, the remaining novel agents discussed have proven safe in initial studies and show promise in promoting tissue regeneration and healing corneal ulcers, ocular burns, chemical injuries, and resurfacing epithelial defects.

Additional clinical evidence and experience with indevelopment agents should potentially offer additional therapeutic options for practitioners. There is no doubt we have much to learn, discover, and improve in order to be able to rescue vision impairments, especially in more severe cases.

Acknowledgements The authors would like to thank the National Eye Institute and National Institutes of Health (NIH) for their support (EY030028 - DK). The authors declare no conflicts of interest. The authors contributed to the preparation of this article in accordance to authorship guidelines and standards.

\section{Declarations}

Funding The authors received no specific funding for conducting this review.

Conflicts of interest All authors declare that they have no conflicts of interest/competing interests.

\section{Ethics approval Not applicable.}

Consent to participate All clinical data shown, was obtained following written consent by the patient and as part of routine ophthalmological exam.

Consent for publication The data is available for publication. No connection/links to the patient(s) is to be provided, as mandated by HIPAA.

Data availability Not applicable.

Code availability Not applicable.

Authors' contributions K.M.R. and D.K. proposed the outline and supervised the project. D.H.D. performed the literature search and wrote the manuscript. K.M.R. and D.K critically revised the first draft. All authors have proofread and approved the final manuscript.

Open Access This article is licensed under a Creative Commons Attribution-NonCommercial 4.0 International License, which permits any non-commercial use, sharing, adaptation, distribution and reproduction in any medium or format, as long as you give appropriate credit to the original author(s) and the source, provide a link to the Creative Commons licence, and indicate if changes were made. The images or other third party material in this article are included in the article's Creative Commons licence, unless indicated otherwise in a credit line to the material. If material is not included in the article's Creative Commons licence and your intended use is not permitted by statutory regulation or exceeds the permitted use, you will need to obtain permission directly from the copyright holder. To view a copy of this licence, visit http://creativecommons.org/licenses/by-nc/4.0/.

\section{References}

1. Yang AY, Chow J, Liu J. corneal innervation and sensation: the eye and beyond. Yale J Biol Med. 2018;91:13-21.

2. Goerig M, Bacon D, van Zundert A. Carl Koller, cocaine, and local anesthesia: some less known and forgotten facts. Reg Anesth Pain Med. 2012;37:318-24.

3. Swaminathan A, Otterness K, Milne K, Rezaie S. The safety of topical anesthetics in the treatment of corneal abrasions: a review. J Emerg Med. 2015;49:810-5.

4. Ball IM, Seabrook J, Desai N, Allen L, Anderson S. Dilute proparacaine for the management of acute corneal injuries in the emergency department. CJEM. 2010;12:389-96.

5. McGee HT, Fraunfelder FW. Toxicities of topical ophthalmic anesthetics. Expert Opin Drug Saf. 2007;6:637-40.

6. Pharmakakis NM, Katsimpris JM, Melachrinou MP, Koliopoulos JX. Corneal complications following abuse of topical anesthetics. Eur J Ophthalmol. 2002;12:373-8.

7. Yagci A, Bozkurt B, Egrilmez S, Palamar M, Ozturk BT, Pekel $\mathrm{H}$. Topical anesthetic abuse keratopathy: a commonly overlooked health care problem. Cornea. 2011;30:571-5.

8. Sansanayudh W, Phansucharitthai T, Sansanayudh N. The effect of cold tetracaine on the severity of burning sensation upon instillation. Clin Ophthalmol. 2018;12:2377-82.

9. Li SF, Flannigan K, Lupow J. Discomfort and tetracaine. Ophthalmology. 2006;113:164.

10. Akten [Internet]. [cited 6 Sep 2021]. https://www.rxlist.com/ akten-drug.htm.

11. Nomura K, Singer DE, Aquavella JV. Corneal sensation after topical anesthesia. Cornea. 2001;20:191-3.

12. Kaimbo WKD. Anaphylactic shock after fluorescein staining corneal abrasion. A case report. Bull Soc Belge Ophtalmol. 2011;317:29-31.

13. Mark B. Abelson, MD, and Avner Ingerman. The Dye-namics of Dry-Eye Diagnosis [Internet]. 2005 [cited 6 Sep 2021]. https:// www.reviewofophthalmology.com/article/the-dye-namics-ofdry-eye-diagnosis.

14. Korb DR, Herman JP, Finnemore VM, Exford JM, Blackie CA. An evaluation of the efficacy of fluorescein, rose bengal, lissamine green, and a new dye mixture for ocular surface staining. Eye Contact Lens. 2008;34:61-4.

15. AAO. 2018-2019 Basic and Clinical Science Course, Section 08: External Disease and Cornea EBook. 2018.

16. Kim J. The use of vital dyes in corneal disease. Curr Opin Ophthalmol. 2000;11:241-7.

17. Kong X-H, Zhao Y, Chen Z, Zeng L, Han R, Dong X-Q, et al. A Randomized Controlled Trial of the Effect of $0.01 \%$ Atropine Eye Drops Combined with Auricular Acupoint Stimulation on Myopia Progression. J Ophthalmol. 2021; 5585441.

18. Jeon GS, Hong IH, Lee JH, Song TG, Lee TY, Han JR. Analysis of treatment response about low-dose $(0.01 \%)$ atropine eye-drops in myopic children. Eur J Ophthalmol. 2021;11206721211038817.

19. Saxena R, Dhiman R, Gupta V, Kumar P, Matalia J, Roy L, et al. Atropine for the treatment of childhood myopia in india: multicentric randomized trial. Ophthalmology. 2021;128:1367-9.

20. van Mil JWF. Sean C Sweetman (Ed): The Martindale, the complete dug reference, 37th edn [Internet]. Int J Clin Pharm. 2011. https://doi.org/10.1007/s11096-011-9543-9

21. Lim DL, Batilando M, Rajadurai VS. Transient paralytic ileus following the use of cyclopentolate-phenylephrine eye drops during screening for retinopathy of prematurity. J Paediatr Child Health. 2003;39:318-20.

22. Price MO, Feng MT, Scanameo A, Price FW Jr. Loteprednol etabonate $0.5 \%$ gel vs. prednisolone acetate $1 \%$ solution after 
descemet membrane endothelial keratoplasty: prospective randomized trial. Cornea. 2015;34:853-8.

23. Rajeev A, Gupta G, Adhikari KM, Yadav AK, Sathyamoorthy M. Neurotoxic effects of topical cyclopentolate. Armed Forces Med J India. 2010;66:288-9.

24. Lux A-L, Degoumois A, Barjol A, Mouriaux F, Denion E. Combination of $5 \%$ phenylephrine and $0.5 \%$ tropicamide eyedrops for pupil dilation in neonates is twice as effective as $0.5 \%$ tropicamide eyedrops alone. Acta Ophthalmol. 2017;95:165-9.

25. Renner UD, Oertel R, Kirch W. Pharmacokinetics and pharmacodynamics in clinical use of scopolamine. Ther Drug Monit. 2005;27:655-65.

26. Samudre SS, Lattanzio FA, Williams PB, Sheppard JD. Comparison of Topical Steroids for Acute Anterior Uveitis [Internet]. J Ocular Pharmacol Therap. 2004. https://doi.org/10.1089/jop. 2004.20.533.

27. Bartlett JD. Clinical ocular pharmacology. Elsevier; 2013.

28. Palioura S, Henry CR, Amescua G, Alfonso EC. Role of steroids in the treatment of bacterial keratitis. Clin Ophthalmol. 2016;10:179-86.

29. Marlowe ZT, Davio SR. Dose uniformity of loteprednol etabonate ophthalmic gel $(0.5 \%)$ compared with branded and generic prednisolone acetate ophthalmic suspension (1\%). Clin Ophthalmol. 2014;8:23-9.

30. Bodor N, Buchwald P. Ophthalmic drug design based on the metabolic activity of the eye: soft drugs and chemical delivery systems. AAPS J. 2005;7:E820-33.

31. Amon M, Busin M. Loteprednol etabonate ophthalmic suspension $0.5 \%$ : efficacy and safety for postoperative anti-inflammatory use. Int Ophthalmol. 2012;32:507-17.

32. Sheppard JD, Toyos MM, Kempen JH, Kaur P, Foster CS. Difluprednate $0.05 \%$ versus prednisolone acetate $1 \%$ for endogenous anterior uveitis: a phase III, multicenter, randomized study. Invest Ophthalmol Vis Sci. 2014;55:2993-3002.

33. Slabaugh MA, Herlihy E, Ongchin S, van Gelder RN. Efficacy and potential complications of difluprednate use for pediatric uveitis. Am J Ophthalmol. 2012;153:932-8.

34. Albietz J. Ophthalmic Drug Facts 2005, 6th edition: Jimmy D Bartlett OD, DOS [Internet]. Clinical and Experimental Optometry. 2005. p. 263-4. https://doi.org/10.1111/j.14440938.2005.tb06708.x

35. Pleyer U, Ursell PG, Rama P. Intraocular pressure effects of common topical steroids for post-cataract inflammation: are they all the same? Ophthalmol Ther. 2013;2:55-72.

36. Fan DSP, Yu CBO, Chiu TYH, Wong CY, Ng JSK, Pang CP, et al. Ocular-hypertensive and anti-inflammatory response to rimexolone therapy in children. Arch Ophthalmol. 2003;121:1716-21.

37. Gaballa SA, Kompella UB, Elgarhy O, Alqahtani AM, Pierscionek B, Alany RG, et al. Corticosteroids in ophthalmology: drug delivery innovations, pharmacology, clinical applications, and future perspectives. Drug Deliv Transl Res. 2021;11:866-93.

38. Sergiyenko N, Sukhina L, Bezdetko P, Kovalenko Y, Nikitin N, Merzbacher M, et al. Hydrocortisone concentration influences time to clinically significant healing of acute inflammation of the ocular surface and adnexa - results from a double-blind randomized controlled trial. BMC Ophthalmol. 2014;14:64.

39. Hong S, Kim T, Chung S-H, Kim EK, Seo KY. Recurrence after topical nonpreserved methylprednisolone therapy for keratoconjunctivitis sicca in Sjögren's syndrome. J Ocul Pharmacol Ther. 2007;23:78-82.

40. Hedayatfar A, Hashemi H, Asgari S, Chee S-P. Comparison of efficacy and ocular surface toxicity of topical preservative-free methylprednisolone and preserved prednisolone in the treatment of acute anterior uveitis. Cornea. 2014;33:366-72.
41. Brandsdorfer A, Patel SH, Chuck RS. The role of perioperative nonsteroidal anti-inflammatory drugs use in cataract surgery. Curr Opin Ophthalmol. 2019;30:44-9.

42. Maca SM, Amon M, Findl O, Kahraman G, Barisani-Asenbauer T. Efficacy and tolerability of preservative-free and preserved diclofenac and preserved ketorolac eyedrops after cataract surgery. Am J Ophthalmol. 2010;149:777-84.

43. Schalnus R. Topical nonsteroidal anti-inflammatory therapy in ophthalmology. Ophthalmologica. 2003;217:89-98.

44. Cho H, Wolf KJ, Wolf EJ. Management of ocular inflammation and pain following cataract surgery: focus on bromfenac ophthalmic solution. Clin Ophthalmol. 2009;3:199-210.

45. Goldstein MH, Silva FQ, Blender N, Tran T, Vantipalli S. Ocular benzalkonium chloride exposure: problems and solutions. Eye [Internet]. 2021. https://doi.org/10.1038/ s41433-021-01668-x.

46. Lin JC, Rapuano CJ, Laibson PR, Eagle RC Jr, Cohen EJ. Corneal melting associated with use of topical nonsteroidal antiinflammatory drugs after ocular surgery. Arch Ophthalmol. 2000;118:1129-32.

47. Kim SJ, Flach AJ, Jampol LM. Nonsteroidal anti-inflammatory drugs in ophthalmology. Surv Ophthalmol. 2010;55:108-33.

48. Gaynes BI, Fiscella R. Topical nonsteroidal anti-inflammatory drugs for ophthalmic use: a safety review. Drug Saf. 2002;25:233-50.

49. Malhotra M, Majumdar DK. In vitro transcorneal permeation of ketorolac tromethamine from buffered and unbuffered aqueous ocular drops. Indian J Exp Biol. 1997;35:941-7

50. Transmucosal Permeation of Topically Applied Diclofenac and Piroxicam [Internet]. [cited 6 Sep 2021]. http://www.jarcet. com/articles/Vol3Iss3/VanDerBikl.htm.

51. Narváez J, Kroll P, Guzek JP. Effect of topical diclofenac and ketorolac on patient discomfort and corneal sensitivity. J Refract Surg. 2002;18:145-8.

52. Aragona $P$, Tripodi G, Spinella R, Laganà E, Ferreri G. The effects of the topical administration of non-steroidal antiinflammatory drugs on corneal epithelium and corneal sensitivity in normal subjects. Eye. 2000;14(Pt 2):206-10.

53. Waterbury LD, Silliman D, Jolas T. Comparison of cyclooxygenase inhibitory activity and ocular anti-inflammatory effects of ketorolac tromethamine and bromfenac sodium. Curr Med Res Opin. 2006;22:1133-40.

54. Kida T, Kozai S, Takahashi H, Isaka M, Tokushige H, Sakamoto T. Pharmacokinetics and efficacy of topically applied nonsteroidal anti-inflammatory drugs in retinochoroidal tissues in rabbits. PLoS ONE. 2014;9:e96481.

55. Baklayan GA, Muñoz M. The ocular distribution of (14) C-labeled bromfenac ophthalmic solution $0.07 \%$ in a rabbit model. Clin Ophthalmol. 2014;8:1717-24.

56. Wentz SM, Price F, Harris A, Siesky B, Ciulla T. Efficacy and safety of bromfenac $0.075 \%$ formulated in DuraSite for pain and inflammation in cataract surgery. Expert Opin Pharmacother. 2019;20:1703-9.

57. Guimaraes de Souza R, Yu Z, Stern ME, Pflugfelder SC, de Paiva CS. Suppression of Th1-mediated Keratoconjunctivitis sicca by lifitegrast. J Ocul Pharmacol Ther. 2018;34:543-9.

58. Patel J, Franko J. Lifitegrast ophthalmic solution 5\% (Xiidra) for dry eye disease. Am Fam Physician. 2018;98:119-20.

59. Sheppard JD, Torkildsen GL, Lonsdale JD, D'Ambrosio FA $\mathrm{Jr}$, McLaurin EB, Eiferman RA, et al. Lifitegrast ophthalmic solution $5.0 \%$ for treatment of dry eye disease: results of the OPUS-1 phase 3 study. Ophthalmology. 2014;121:475-83.

60. Huang J, Su W, Chen X, Cheng X, Dai Y, Han L, et al. Doxycycline attenuates endotoxin-induced uveitis by prostaglandin E2-EP4 signaling. Invest Ophthalmol Vis Sci. 2015;56:6686-93. 
61. Nissinen L, Kähäri V-M. Matrix metalloproteinases in inflammation. Biochim Biophys Acta. 2014;1840:2571-80.

62. Onghanseng N, Ng SM, Halim MS, Nguyen QD. Oral antibiotics for chronic blepharitis. Cochrane Database Syst Rev. 2021;6:CD013697.

63. Aronowicz JD, Shine WE, Oral D, Vargas JM, McCulley JP. Short term oral minocycline treatment of meibomianitis. Br J Ophthalmol. 2006;90:856-60.

64. Hutton D. Minocycline shows promise in dry eye trial [Internet]. Ophthalmology Times. 2021 [cited 6 Sep 2021]. https:// www.ophthalmologytimes.com/view/minocycline-shows-promi se-in-dry-eye-trial.

65. Cyphert EL, Wallat JD, Pokorski JK, von Recum HA. Erythromycin modification that improves its acidic stability while optimizing it for local drug delivery. Antibiotics (Basel) Internet. 2017. https://doi.org/10.3390/antibiotics6020011.

66. Friedlaender MH, Protzko E. Clinical development of $1 \%$ azithromycin in DuraSite, a topical azalide anti-infective for ocular surface therapy. Clin Ophthalmol. 2007;1:3-10.

67. Dominick L, Opitz JSH. Review of azithromycin ophthalmic $1 \%$ solution (AzaSite ${ }^{\circledR}$ ) for the treatment of ocular infections. Ophthalmol Eye Dis. 2012;4:1.

68. John T, Shah AA. Use of azithromycin ophthalmic solution in the treatment of chronic mixed anterior blepharitis. Ann Ophthalmol. 2008;40:68-74.

69. Ness PJ, Mamalis N, Werner L, Maddula S, Davis DK, Donnenfeld ED, et al. An anterior chamber toxicity study evaluating Besivance, AzaSite, and Ciprofloxacin. Am J Ophthalmol. 2010;150:498-504.e1.

70. Qazi Y, Wong G, Monson B, Stringham J, Ambati BK. Corneal transparency: genesis, maintenance and dysfunction. Brain Res Bull. 2010;81:198-210.

71. Grobe GM, Reichl S. Characterization of vitamin C-induced cell sheets formed from primary and immortalized human corneal stromal cells for tissue engineering applications. Cells Tissues Organs. 2013;197:283-97.

72. Lee MY, Chung SK. Treatment of corneal neovascularization by topical application of ascorbic acid in the rabbit model. Cornea. 2012;31:1165-9.

73. Chen J, Lan J, Liu D, Backman LJ, Zhang W, Zhou Q, et al. Ascorbic acid promotes the stemness of corneal epithelial stem/ progenitor cells and accelerates epithelial wound healing in the cornea. Stem Cells Transl Med. 2017;6:1356-65.

74. Cho Y-W, Yoo W-S, Kim S-J, Chung I-Y, Seo S-W, Yoo J-M. Efficacy of systemic vitamin $\mathrm{C}$ supplementation in reducing corneal opacity resulting from infectious keratitis. Medicine. 2014;93:e125.

75. Srinivasan M, Mascarenhas J, Rajaraman R, Ravindran M, Lalitha P, Glidden DV, et al. Corticosteroids for bacterial keratitis: the Steroids for Corneal Ulcers Trial (SCUT). Arch Ophthalmol. 2012;130:143-50.

76. Jirsova K, Jones GLA. Amniotic membrane in ophthalmology: properties, preparation, storage and indications for grafting-a review. Cell Tissue Bank. 2017;18:193-204.

77. Dinarello CA. Historical insights into cytokines. Eur J Immunol. 2007;37(Suppl 1):S34-45.

78. Turner MD, Nedjai B, Hurst T, Pennington DJ. Cytokines and chemokines: at the crossroads of cell signalling and inflammatory disease. Biochim Biophys Acta. 2014;1843:2563-82.

79. Tighe S, Moein H-R, Chua L, Cheng A, Hamrah P, Tseng SCG. Topical cryopreserved amniotic membrane and umbilical cord eye drops promote re-epithelialization in a murine corneal abrasion model. Invest Ophthalmol Vis Sci. 2017;58:1586-93.

80. Rennie K, Gruslin A, Hengstschläger M, Pei D, Cai J, Nikaido T, et al. Applications of amniotic membrane and fluid in stem cell biology and regenerative medicine. Stem Cells Int. 2012;721538.
81. Murri MS, Moshirfar M, Birdsong OC, Ronquillo YC, Ding Y, Hoopes PC. Amniotic membrane extract and eye drops: a review of literature and clinical application. Clin Ophthalmol. 2018;12:1105-12.

82. Cooke M, Tan EK, Mandrycky C, He H, O'Connell J, Tseng SCG. Comparison of cryopreserved amniotic membrane and umbilical cord tissue with dehydrated amniotic membrane/chorion tissue. J Wound Care. 2014;23(465-74):476.

83. Sheha H, Liang L, Li J, Tseng SCG. Sutureless amniotic membrane transplantation for severe bacterial keratitis. Cornea. 2009;28:1118-23.

84. Pachigolla G, Prasher P, Di Pascuale MA, McCulley JP, McHenry JG, Mootha VV. Evaluation of the role of ProKera in the management of ocular surface and orbital disorders. Eye Contact Lens. 2009;35:172-5.

85. Cheng AMS, Zhao D, Chen R, Yin HY, Tighe S, Sheha H, et al. Accelerated restoration of ocular surface health in dry eye disease by self-retained cryopreserved amniotic membrane. Ocul Surf. 2016;14:56-63.

86. Walkden A. Amniotic membrane transplantation in ophthalmology: an updated perspective. Clin Ophthalmol. 2020;14:2057-72.

87. Mimouni M, Trinh T, Sorkin N, Cohen E, Santaella G, Rootman DS, et al. Sutureless dehydrated amniotic membrane for persistent epithelial defects. Eur J Ophthalmol. 2021;11206721211011354.

88. Roy A, Griffiths S. Intermediate layer contribution in placental membrane allografts. J Tissue Eng Regen Med. 2020;14:1126-35.

89. Freire V, Andollo N, Etxebarria J, Durán JA, Morales M-C. In vitro effects of three blood derivatives on human corneal epithelial cells. Invest Ophthalmol Vis Sci. 2012;53:5571-8.

90. Huang C-J, Sun Y-C, Christopher K, Pai AS-I, Lu C-J, Hu F-R, et al. Comparison of corneal epitheliotrophic capacities among human platelet lysates and other blood derivatives. PLoS ONE. 2017; 12:e0171008.

91. Website [Internet]. [cited 6 Sep 2021]. https://www.fda.gov/ vaccines-blood-biologics/blood-blood-products.

92. Mandić JJ, Kozmar A, Kusačić-Kuna S, Jazbec A, Mandić K, Mrazovac D, et al. The levels of 12 cytokines and growth factors in tears: hyperthyreosis vs euthyreosis. Graefes Arch Clin Exp Ophthalmol. 2018;256:845-52.

93. Shtein RM, Shen JF, Kuo AN, Hammersmith KM, Li JY, Weikert MP. Autologous serum-based eye drops for treatment of ocular surface disease: a report by the American Academy of Ophthalmology. Ophthalmology. 2020;127:128-33.

94. Read SP, Rodriguez M, Dubovy S, Karp CL, Galor A. Treatment of refractory filamentary keratitis with autologous serum tears. Eye Contact Lens. 2017;43:e16-8.

95. Huang F-C, Chen W-J, Shih M-H. Paederus-induced keratitis. Cornea. 2010;29:941-3.

96. Goto E, Shimmura S, Shimazaki J, Tsubota K. Treatment of superior limbic keratoconjunctivitis by application of autologous serum. Cornea. 2001;20:807-10.

97. Chiang C-C, Lin J-M, Chen W-L, Tsai Y-Y. Allogeneic serum eye drops for the treatment of severe dry eye in patients with chronic graft-versus-host disease. Cornea. 2007;26:861-3.

98. Pan Q, Angelina A, Marrone M, Stark WJ, Akpek EK. Autologous serum eye drops for dry eye. Cochrane Database Syst Rev. 2017;2:CD009327.

99. Kim BY, Riaz KM, Bakhtiari P, Chan CC, Welder JD, Holland EJ, et al. Medically reversible limbal stem cell disease: clinical features and management strategies. Ophthalmology. 2014;121:2053-8.

100. Sharma A, Riaz KM, Gill MS, Patnaik A, Ulahannan SV, Wang JS, et al. Reversible HER2 antibody-drug conjugate-induced 
ocular toxicity. Can J Ophthalmol [Internet]. 2021. https://doi. org/10.1016/j.jcjo.2021.02.028.

101. Kamble N, Sharma N, Maharana PK, Bandivadekar P, Nagpal R, Agarwal T, et al. Evaluation of the role of umbilical cord serum and autologous serum therapy in reepithelialization after keratoplasty: a randomized controlled clinical trial. Eye Contact Lens. 2017;43:324-9.

102. Akcam HT, Unlu M, Karaca EE, Yazici H, Aydin B, Hondur AM. Autologous serum eye-drops and enhanced epithelial healing time after photorefractive keratectomy. Clin Exp Optom. 2018;101:34-7.

103. Campos E, Versura P, Buzzi M, Fontana L, Giannaccare G, Pellegrini M, et al. Blood derived treatment from two allogeneic sources for severe dry eye associated to keratopathy: a multicentre randomised cross over clinical trial. Br J Ophthalmol. 2020;104:1142-7.

104. Versura P, Buzzi M, Giannaccare G, Terzi A, Fresina M, Velati $\mathrm{C}$, et al. Targeting growth factor supply in keratopathy treatment: comparison between maternal peripheral blood and cord blood as sources for the preparation of topical eye drops. Blood Transfus. 2016;14:145-51.

105. Lubkowska A, Dolegowska B, Banfi G. Growth factor content in PRP and their applicability in medicine. J Biol Regul Homeost Agents. 2012;26:3S-22S.

106. Anitua E, Muruzabal F, de la Fuente M, Riestra A, MerayoLloves J, Orive G. PRGF exerts more potent proliferative and anti-inflammatory effects than autologous serum on a cell culture inflammatory model. Exp Eye Res. 2016;151:115-21.

107. Anitua E, de la Fuente M, Muruzabal F, Riestra A, MerayoLloves J, Orive G. Plasma rich in growth factors (PRGF) eye drops stimulates scarless regeneration compared to autologous serum in the ocular surface stromal fibroblasts. Exp Eye Res. 2015;135:118-26.

108. Merayo-Lloves J, Sanchez RM, Riestra AC, Anitua E, Begoña L, Orive G, et al. Autologous plasma rich in growth factors eyedrops in refractory cases of ocular surface disorders. Ophthalmic Res. 2015;55:53-61.

109. Anitua E, Muruzabal F, De la Fuente M, Merayo-Lloves $\mathrm{J}$, Orive G. Effects of heat-treatment on plasma rich in growth factors-derived autologous eye drop. Exp Eye Res. 2014;119:27-34.

110. Balal S, Nitiahpapand R, Hassan A, Than J, Patel A, Kumar B, et al. Finger-prick autologous blood in the treatment of persistent corneal epithelial defects. Cornea. 2020;39:594-7.

111. Than J, Balal S, Wawrzynski J, Nesaratnam N, Saleh GM, Moore $\mathrm{J}$, et al. Fingerprick autologous blood: a novel treatment for dry eye syndrome. Eye. 2017;31:1655-63.

112. Pujari R, Deshmukh R, Sheth C, Rajan MS. Maternal fingerprick allogenic blood for persistent corneal epithelial defects. BMJ Case Rep [Internet]. 2021. https://doi.org/10.1136/ bcr-2020-241138.

113. Menghini M, Knecht PB, Kaufmann C, Kovacs R, Watson SL, Landau K, et al. Treatment of traumatic corneal abrasions: a three-arm, prospective, randomized study. Ophthalmic Res. 2013;50:13-8.

114. Triharpini NN, Gede Jayanegara IW, Handayani AT, Widiana IGR. Comparison between bandage contact lenses and pressure patching on the erosion area and pain scale in patients with corneal erosion. Asia Pac J Ophthalmol (Phila). 2015;4:97-100.

115. Blackmore SJ. The use of contact lenses in the treatment of persistent epithelial defects. Cont Lens Anterior Eye. 2010;33:239-44.

116. Weyns M, Koppen C, Tassignon M-J. Scleral contact lenses as an alternative to tarsorrhaphy for the long-term management of combined exposure and neurotrophic keratopathy. Cornea. 2013;32:359-61.
117. Trufanov SV. Cyanoacrylate adhesive in surgrical treatment of corneal perforation (clinical case). Vestn Oftalmol. 2020;136:232-6.

118. Taravella MJ, Chang CD. 2-Octyl cyanoacrylate medical adhesive in treatment of a corneal perforation. Cornea. 2001;20:220-1.

119. Garg P, Gopinathan U, Nutheti R, Rao GN. Clinical experience with N-butyl cyanoacrylate tissue adhesive in fungal keratitis. Cornea. 2003;22:405-8.

120. Vote BJ, Elder MJ. Cyanoacrylate glue for corneal perforations: a description of a surgical technique and a review of the literature. Clin Experiment Ophthalmol. 2000;28:437-42.

121. Rana M, Savant V. A brief review of techniques used to seal corneal perforation using cyanoacrylate tissue adhesive. Cont Lens Anterior Eye. 2013;36:156-8.

122. Deshmukh R, Stevenson LJ, Vajpayee R. Management of corneal perforations: an update. Indian J Ophthalmol. 2020;68:7.

123. Duchesne B, Tahi H, Galand A. Use of human fibrin glue and amniotic membrane transplant in corneal perforation. Cornea. 2001;20:230-2.

124. Papadopoulou DN, Sionga A, Karayannopoulou G, Natsis K, Komnenou A, Mangioris G, et al. Experimental application of tissue adhesives in corneal traumas. Eur J Ophthalmol. 2013;23:646-51.

125. Sharma A, Kaur R, Kumar S, Gupta P, Pandav S, Patnaik B, et al. Fibrin glue versus N-butyl-2-cyanoacrylate in corneal perforations. Ophthalmology. 2003;110:291-8.

126. Bhatia SS. Ocular surface sealants and adhesives. Ocul Surf. 2006;4:146-54.

127. Khokhar S, Natung T, Sony P, Sharma N, Agarwal N, Vajpayee $\mathrm{RB}$. Amniotic membrane transplantation in refractory neurotrophic corneal ulcers: a randomized, controlled clinical trial. Cornea. 2005;24:654-60.

128. Acharya M, Gour A, Dave A. Commentary: tarsorrhaphy: a stitch in time. Indian J Ophthalmol. 2020;68:33-4.

129. Website [Internet]. [cited 6 Sep 2021]. https://www.accessdata. fda.gov/drugsatfda_docs/nda/2018/761094Orig1s000TOC.cfm.

130. Scelfo C, Mantagos IS. Neurotrophic keratopathy in pediatric patients. Semin Ophthalmol. 2021;36:289-95.

131. Dua HS, Said DG, Messmer EM, Rolando M, Benitez-Del-Castillo JM, Hossain PN, et al. Neurotrophic keratopathy. Prog Retin Eye Res. 2018;66:107-31.

132. Ahuja AS, Bowden FW III, Robben JL. A Novel Treatment for Neurotrophic Corneal Ulcer Using Topical Cenegermin $\left(\right.$ OXERVATE $\left.^{\mathrm{TM}}\right)$ Containing Recombinant Human Nerve Growth Factor. Cureus. 2020;12:e11724.

133. Soifer M, Gomez-Caraballo M, Venkateswaran N, Jay GW, Perez VL. Associated neurotrophic keratopathy in complex regional pain syndrome. Cornea [Internet]. 2021. https://doi.org/10.1097/ ICO.0000000000002684.

134. Sacchetti M, Bruscolini A, Lambiase A. Cenegermin for the treatment of neurotrophic keratitis. Drugs Today. 2017;53:585-95.

135. Pflugfelder SC, Massaro-Giordano M, Perez VL, Hamrah P, Deng SX, Espandar L, et al. Topical recombinant human nerve growth factor (Cenegermin) for neurotrophic keratopathy: a multicenter randomized vehicle-controlled pivotal trial. Ophthalmology. 2020;127:14-26.

136. Weinlander E, Ling J, Reddy A, Nallasamy N. Epithelial plaque formation secondary to recombinant human nerve growth factor. Cornea. 2020;39:1174-6.

137. Ferrari MP, Mantelli F, Sacchetti M, Antonangeli MI, Cattani F, D'Anniballe G, et al. Safety and pharmacokinetics of escalating doses of human recombinant nerve growth factor eye drops in a double-masked, randomized clinical trial. BioDrugs. 2014;28:275-83.

138. Website [Internet]. [cited 6 Sep 2021]. https://oxervate.com/taking-oxervate/. 
139. Wang AL, Weinlander E, Metcalf BM, Barney NP, Gamm DM, Nehls SM, et al. Use of topical insulin to treat refractory neurotrophic corneal ulcers. Cornea. 2017;36:1426-8.

140. Galvis V, Niño CA, Tello A, Grice JM, Gómez MA. Topical insulin in neurotrophic keratopathy after resection of acoustic neuroma. Arch Soc Esp Oftalmol. 2019;94:100-4.

141. Fai S, Ahem A, Mustapha M, Mohd Noh UK, Bastion M-LC. Randomized controlled trial of topical insulin for healing corneal epithelial defects induced during vitreoretinal surgery in diabetics. Asia Pac J Ophthalmol (Phila). 2017;6:418-24.

142. Morishige N, Morita Y, Yamada N, Nishida T, Sonoda K-H. Congenital hypoplastic trigeminal nerve revealed by manifestation of corneal disorders likely caused by neural factor deficiency. Case Rep Ophthalmol. 2014;5:181-5.

143. Yamada N, Matsuda R, Morishige N, Yanai R, Chikama T-I, Nishida T, et al. Open clinical study of eye-drops containing tetrapeptides derived from substance $P$ and insulin-like growth factor-1 for treatment of persistent corneal epithelial defects associated with neurotrophic keratopathy. Br J Ophthalmol. 2008;92:896-900.

144. Yamada N, Yanai R, Kawamoto K, Nagano T, Nakamura M, Inui M, et al. Promotion of corneal epithelial wound healing by a tetrapeptide (SSSR) derived from IGF-1. Invest Ophthalmol Vis Sci. 2006;47:3286-92.

145. Nishida T, Chikama T-I, Morishige N, Yanai R, Yamada N, Saito J. Persistent epithelial defects due to neurotrophic keratopathy treated with a substance p-derived peptide and insulin-like growth factor 1. Jpn J Ophthalmol. 2007;51:442-7.

146. Dunn SP, Heidemann DG, Chow CYC, Crockford D, Turjman $\mathrm{N}$, Angel J, et al. Treatment of chronic nonhealing neurotrophic corneal epithelial defects with thymosin beta4. Ann N Y Acad Sci. 2010;1194:199-206.

147. Sosne G, Qiu P, Kurpakus-Wheater M, Matthew H. Thymosin beta4 and corneal wound healing: visions of the future. Ann N Y Acad Sci. 2010;1194:190-8.

148. Katzman LR, Jeng BH. Management strategies for persistent epithelial defects of the cornea. Saudi J Ophthalmol. 2014;28:168-72.

149. Ormonde S, Chou C-Y, Goold L, Petsoglou C, Al-Taie R, Sherwin $\mathrm{T}$, et al. Regulation of connexin43 gap junction protein triggers vascular recovery and healing in human ocular persistent epithelial defect wounds. J Membr Biol. 2012;245:381-8.

150. Barritault D, Gilbert-Sirieix M, Rice KL, Siñeriz F, Papy-Garcia D, Baudouin C, et al. RGTA or ReGeneraTing Agents mimic heparan sulfate in regenerative medicine: from concept to curing patients. Glycoconj J. 2017;34:325-38.

151. Sevik MO, Turhan SA, Toker E. Topical treatment of persistent epithelial defects with a matrix regenerating agent. J Ocul Pharmacol Ther. 2018;34:621-7.

152. Chebbi CK, Kichenin K, Amar N, Nourry H, Warnet JM, Barritault D, et al. Pilot study of a new matrix therapy agent (RGTA OTR4120) in treatment-resistant corneal ulcers and corneal dystrophy. J Fr Ophtalmol. 2008;31:465-71.

153. Aifa A, Gueudry J, Portmann A, Delcampe A, Muraine M. Topical treatment with a new matrix therapy agent (RGTA) for the treatment of corneal neurotrophic ulcers. Invest Ophthalmol Vis Sci. 2012;53:8181-5.

154. Bata AM, Witkowska KJ, Wozniak PA, Fondi K, Schmidinger G, Pircher N, et al. Effect of a matrix therapy agent on corneal epithelial healing after standard collagen cross-linking in patients with keratoconus: a randomized clinical trial. JAMA Ophthalmol. 2016;134:1169-76.
155. Hovakimyan M, Stachs O, Céline O, Guthoff RF. Matrix-based regenerating agent for corneal wound healing after collagen cross-linking. Cornea. 2016;35:1638-43.

156. Arvola RPJ, Robciuc A, Holopainen JM. Matrix regeneration therapy: a case series of corneal neurotrophic ulcers. Cornea. 2016;35:451-5.

157. Giannaccare G, Fresina M, Vagge A, Versura P. Synergistic effect of regenerating agent plus cord blood serum eye drops for the treatment of resistant neurotrophic keratitis: a case report and a hypothesis for pathophysiologic mechanism. Int Med Case Rep J. 2015;8:277-81.

158. Bonini S, Lambiase A, Rama P, Sinigaglia F, Allegretti M, Chao $\mathrm{W}$, et al. Phase II randomized, double-masked, vehicle-controlled trial of recombinant human nerve growth factor for neurotrophic keratitis. Ophthalmology. 2018;125:1332-43.

159. Serrano-Giménez R, Contreras-Macías E, García-Bernal A, Fobelo-Lozano MJ. Insulin eye drops for treating corneal ulcer in a non-diabetic patient: regarding a case. Farm Hosp. 2020;44:297-9.

160. Nakamura M, Kawahara M, Morishige N, Chikama T, Nakata $\mathrm{K}$, Nishida T. Promotion of corneal epithelial wound healing in diabetic rats by the combination of a substance P-derived peptide (FGLM-NH2) and insulin-like growth factor-1. Diabetologia. 2003;46:839-42.

161. Yanai R, Nishida T, Hatano M, Uchi S-H, Yamada N, Kimura $\mathrm{K}$. Role of the neurokinin-1 receptor in the promotion of corneal epithelial wound healing by the peptides FGLM-NH2 and SSSR in neurotrophic keratopathy. Invest Ophthalmol Vis Sci. 2020;61:29.

162. Sosne G, Christopherson PL, Barrett RP, Fridman R. Thymosinbeta4 modulates corneal matrix metalloproteinase levels and polymorphonuclear cell infiltration after alkali injury. Invest Ophthalmol Vis Sci. 2005;46:2388-95.

163. Kim CE, Kleinman HK, Sosne G, Ousler GW, Kim K, Kang S, et al. RGN-259 (thymosin $\beta 4$ ) improves clinically important dry eye efficacies in comparison with prescription drugs in a dry eye model. Sci Rep. 2018;8:10500.

164. Sosne G, Dunn SP, Kim C. Thymosin $\beta 4$ significantly improves signs and symptoms of severe dry eye in a phase 2 randomized trial. Cornea. 2015;34:491-6.

165. Sosne G, Ousler GW. Thymosin beta 4 ophthalmic solution for dry eye: a randomized, placebo-controlled, Phase II clinical trial conducted using the controlled adverse environment $\left(\mathrm{CAE}^{\mathrm{TM}}\right)$ model. Clin Ophthalmol. 2015;9:877-84.

166. Brignole-Baudouin F, Warnet JM, Barritault D, Baudouin C. RGTA-based matrix therapy in severe experimental corneal lesions: safety and efficacy studies. J Fr Ophtalmol. 2013;36:740-7.

167. Chappelet M-A, Bernheim D, Chiquet C, Aptel F. Effect of a new matrix therapy agent in persistent epithelial defects after bacterial keratitis treated with topical fortified antibiotics. Cornea. 2017;36:1061-8.

168. Guerra M, Marques S, Gil JQ, Campos J, Ramos P, Rosa AM, et al. Neurotrophic keratopathy: therapeutic approach using a novel matrix regenerating agent. J Ocul Pharmacol Ther. 2017;33:662-9. 


\section{Authors and Affiliations}

\section{Deanna H. Dang ${ }^{1} \cdot$ Kamran M. Riaz ${ }^{1}$ - Dimitrios Karamichos ${ }^{2,3,4}$}

$\triangle$ Dimitrios Karamichos

Dimitrios.Karamichos@unthsc.edu

Deanna H. Dang

Deanna-Dang@ouhsc.edu

Kamran M. Riaz

Kamran-Riaz@dmei.org

1 Department of Ophthalmology, Dean McGee Eye Institute, University of Oklahoma Health Sciences Center, Oklahoma City, OK, USA
2 North Texas Eye Research Institute, University of North Texas Health Science Center, Fort Worth, TX 76107, USA

3 Department of Pharmaceutical Sciences, University of North Texas Health Science Center, Fort Worth, TX 76107, USA

4 Department of Pharmacology and Neuroscience, University of North Texas Health Science Center, Fort Worth, TX 76107, USA 